\title{
Poothan Kali Songs : an analysis of their types, themes and functions
}

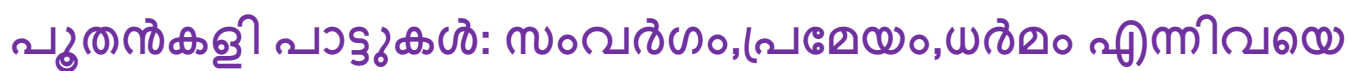
(ே)

\section{H.K. Santhosh a, ${ }^{*}$}

a Department of Malayalam, SNGS College Pattambi, Mele Pattambi, Kerala-679306, India.

*Corresponding author Ph: +91 9037852621; Email: santhoshhrishikesh@gmail.com S

DOI: https://doi.org/10.34256/ijmrd2114

Received: 26-03-2021; Accepted: 28-03-2021 Published: 30-03-2021

Abstract: 'Panappoothan' is an art form performed by the Pana community at festivals at the Bhagvati temples in old Valluvanad district of Kerala. Unlike the Poothan performance of other castes, Panans also sing songs in their Poothan and Andi kali. They perform 'anchati pattukal', hymns and 'kummi pattukal' along with the performance. These songs have not yet been recorded in our folk song tradition or literary history. This essay analyzes these songs descriptively and determines the folk identity expressed in it.

Keywords: Poothan kali, Panan, Folk songs, Valluvanad.

Language: Malayalam

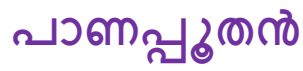

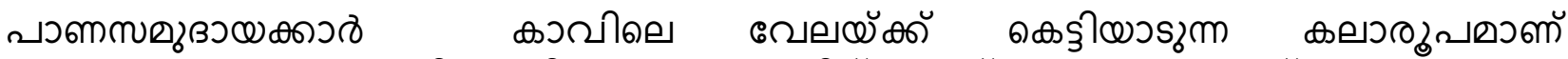

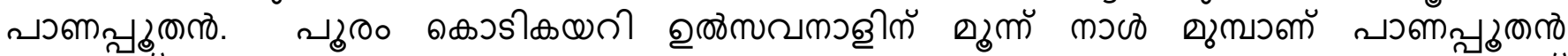

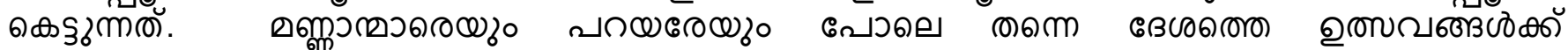

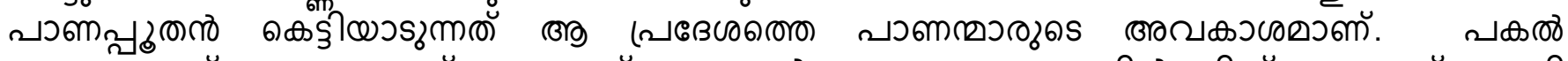

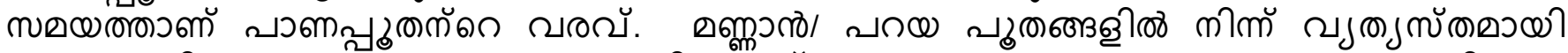

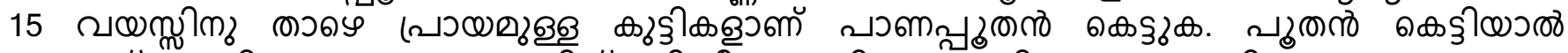

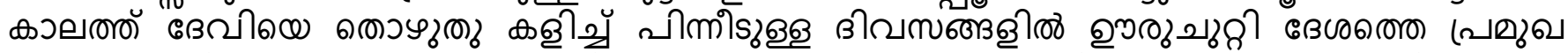

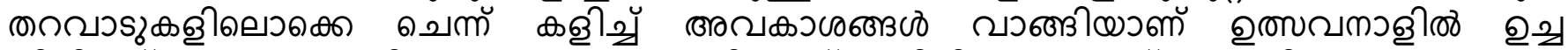

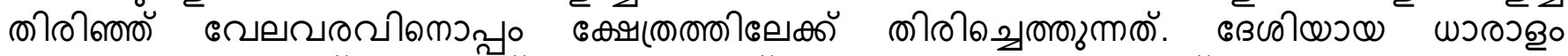

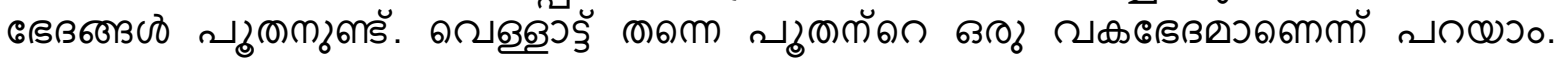

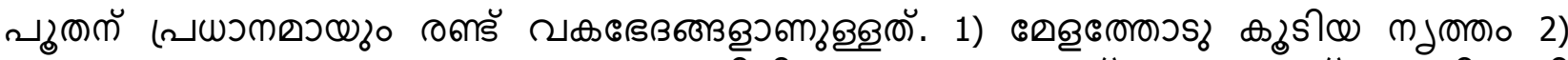

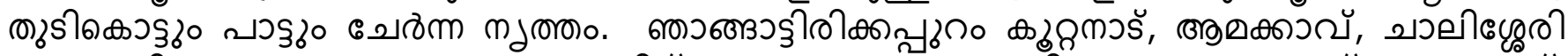

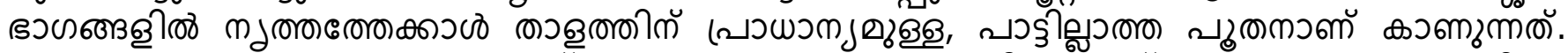

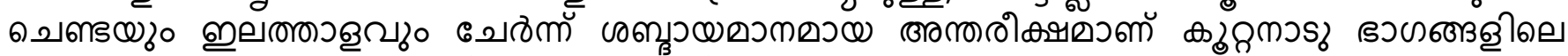

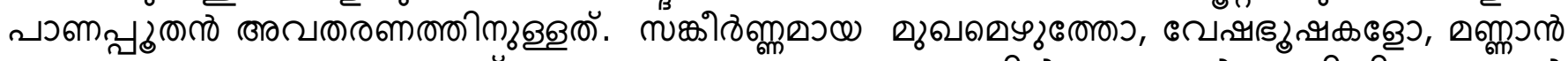

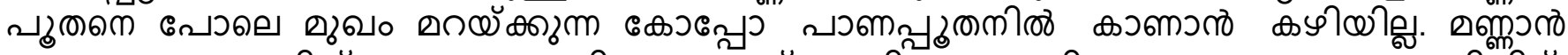

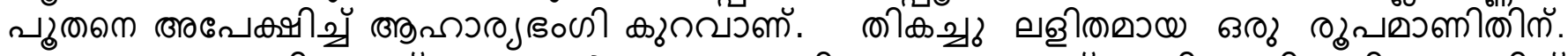

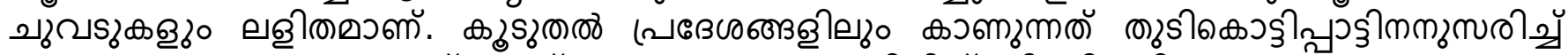

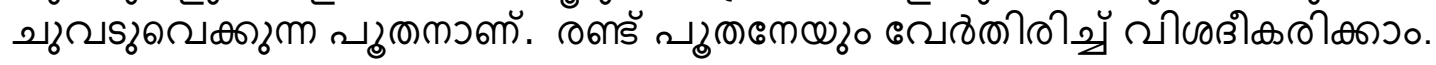

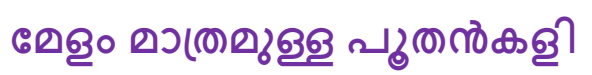

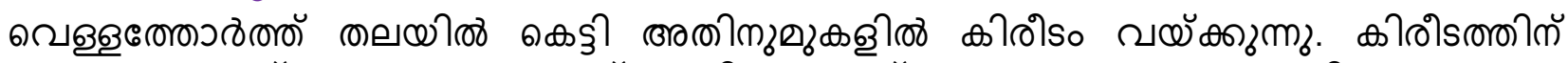

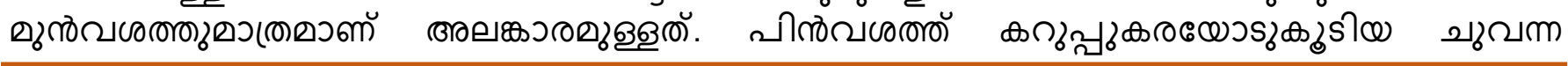




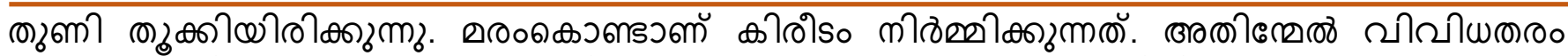

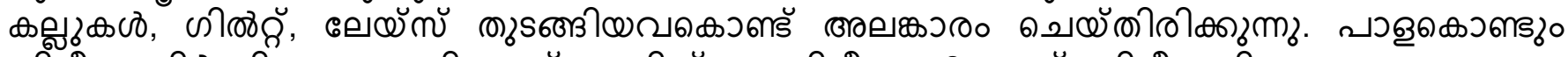

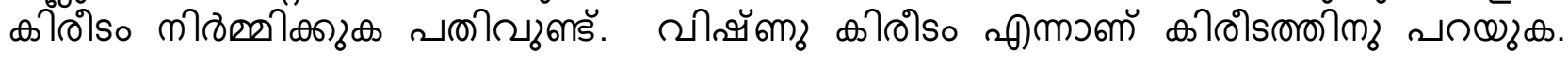

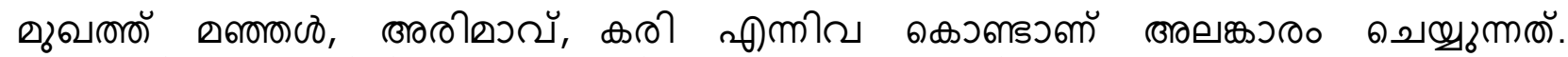

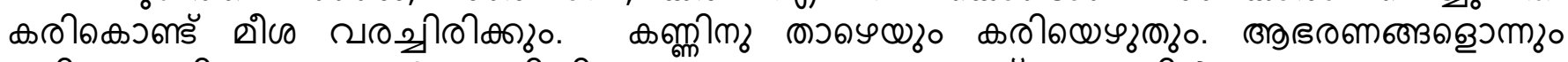

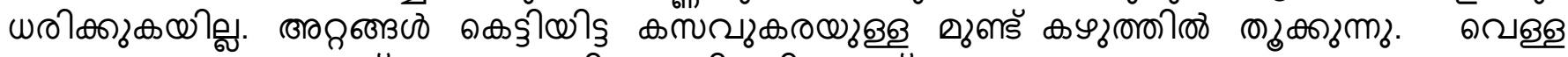

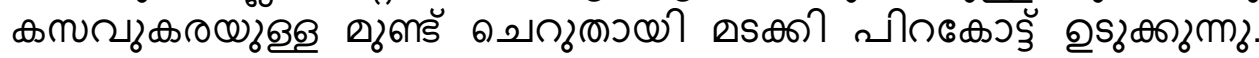

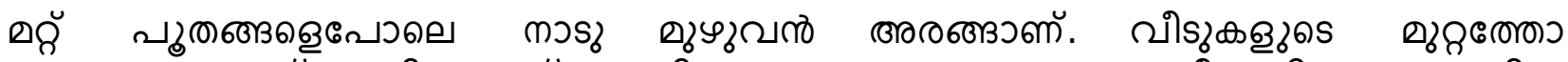

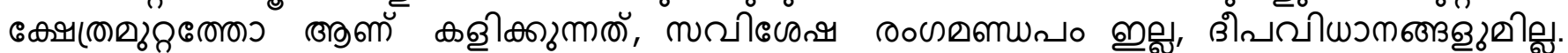

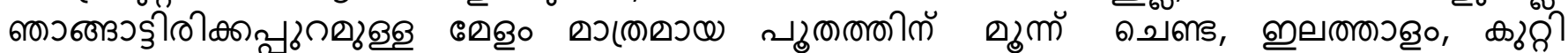

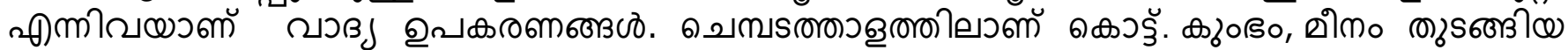

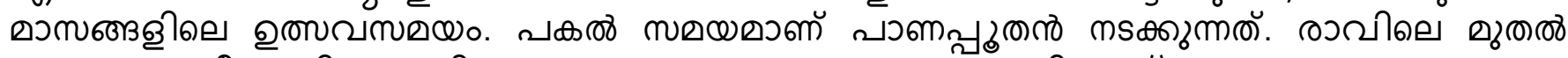

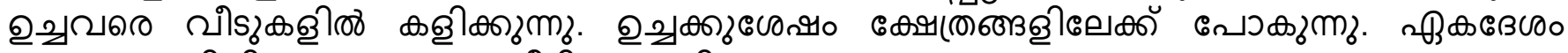

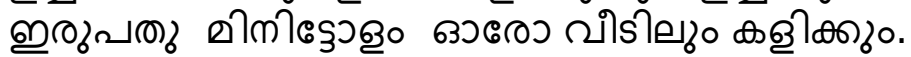

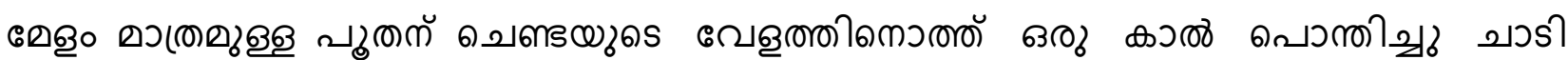

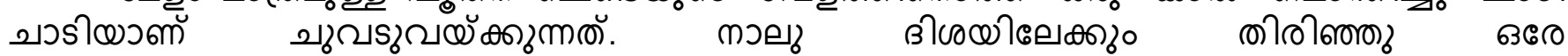

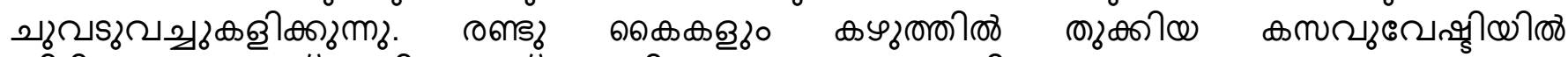

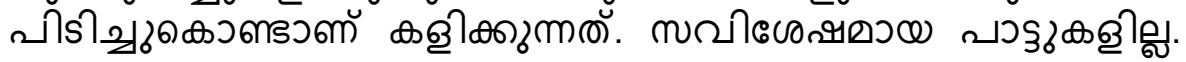

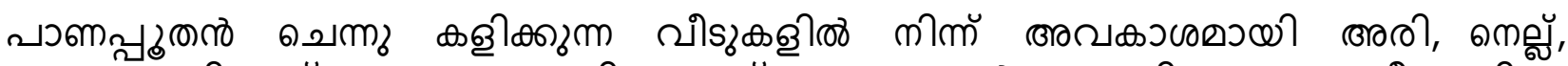

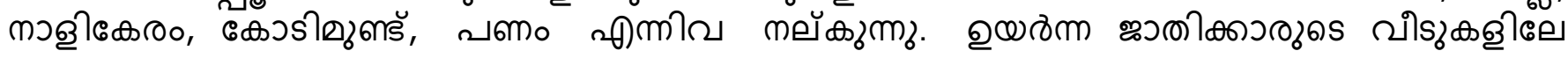

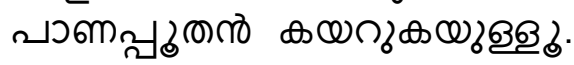

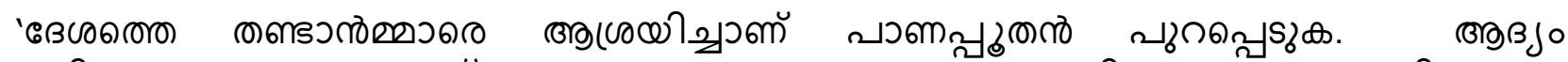

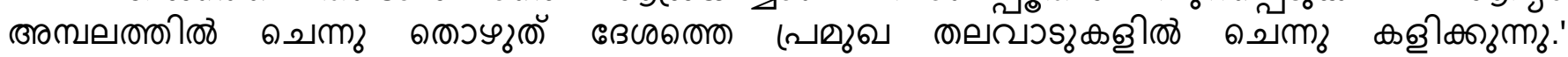

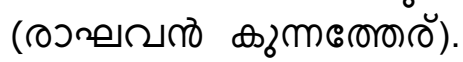

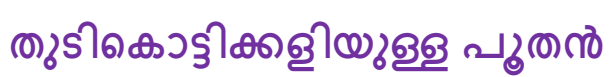

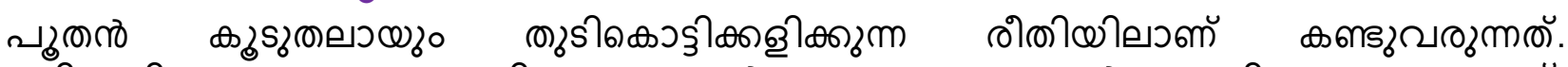

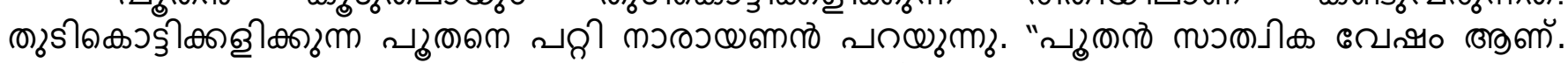

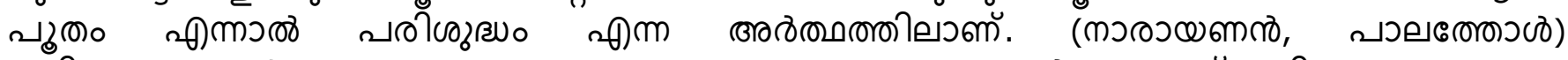

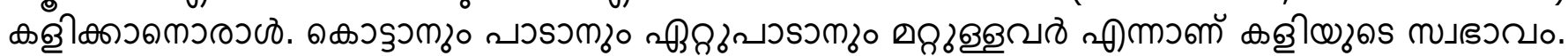

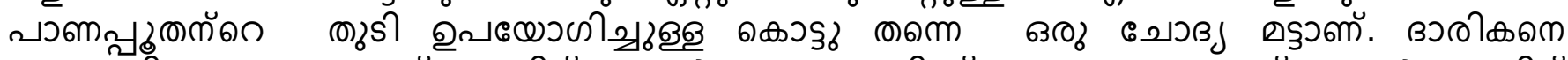

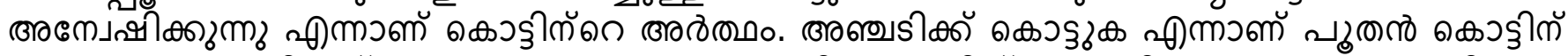

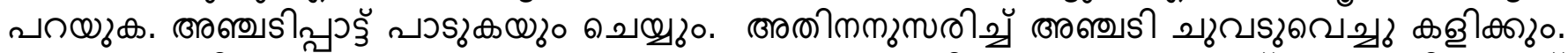

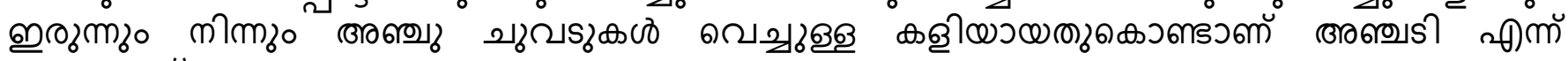

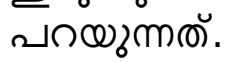

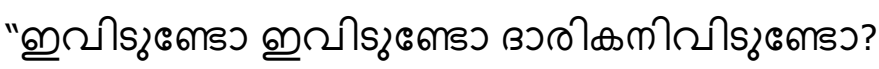

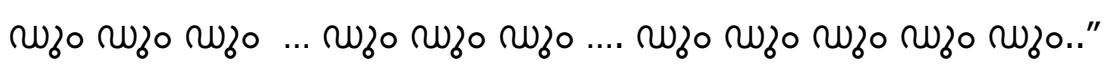

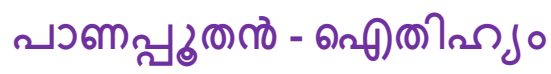

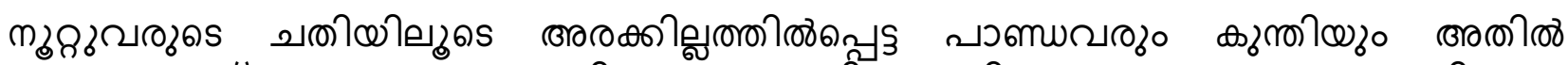

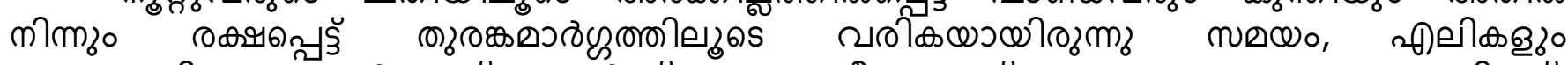

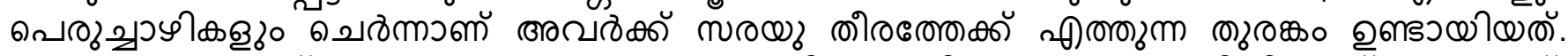

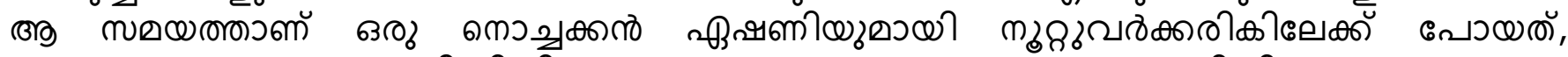

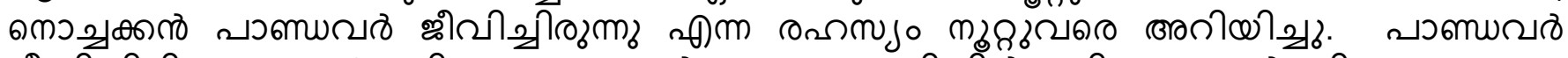

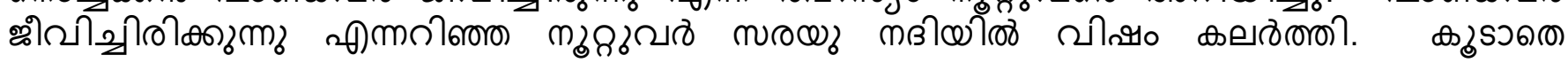




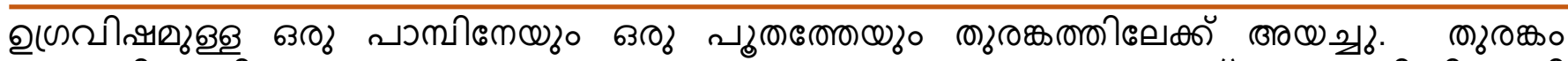

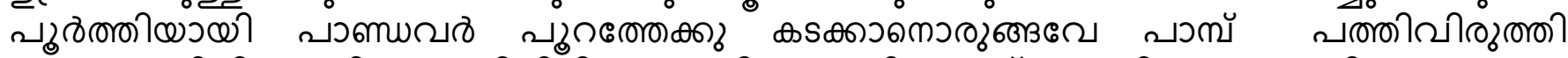

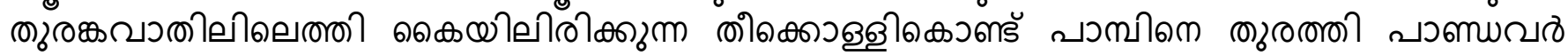

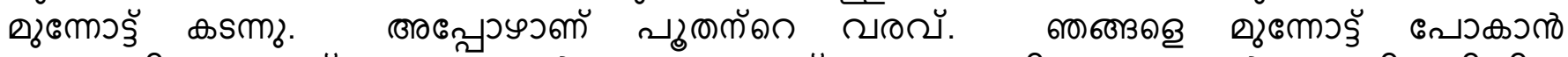

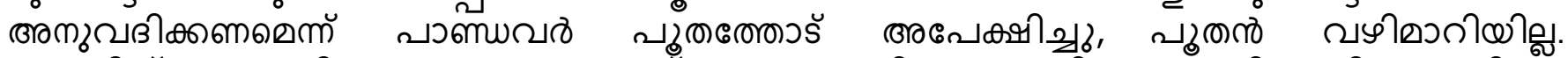

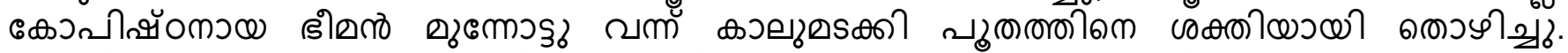

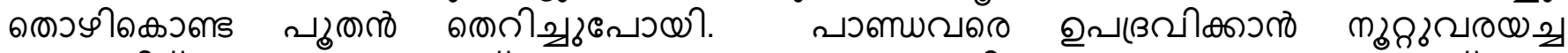

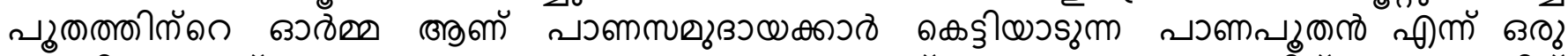

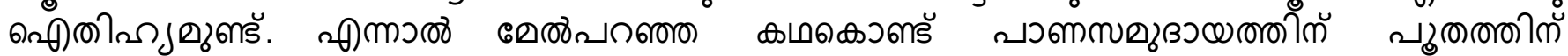

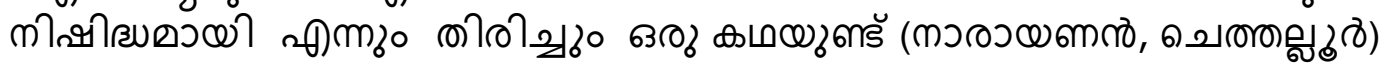

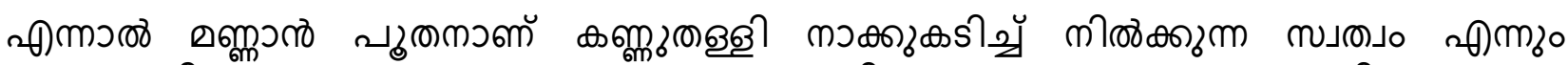

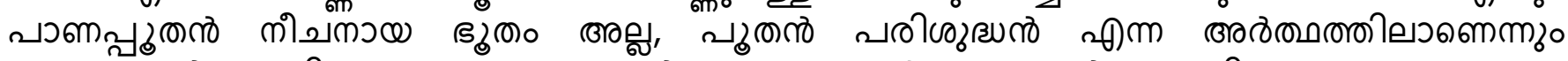

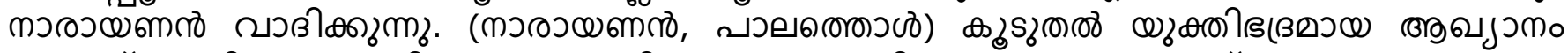

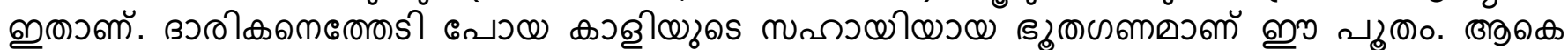

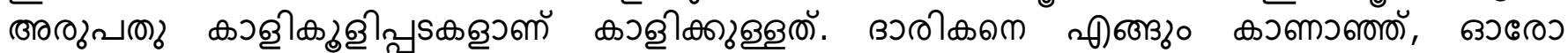

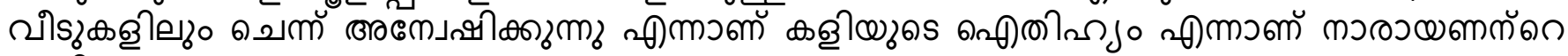

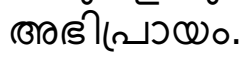

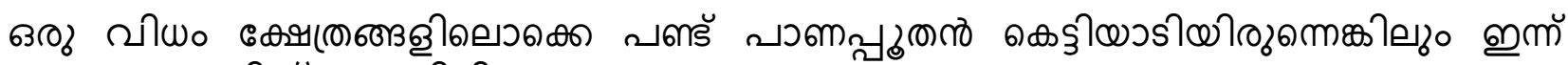

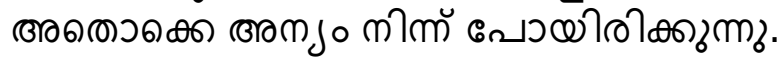

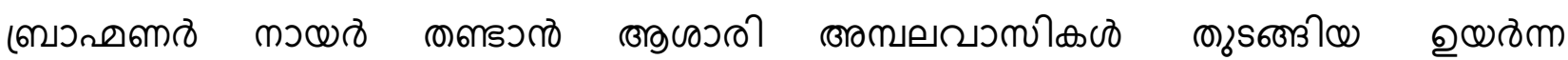

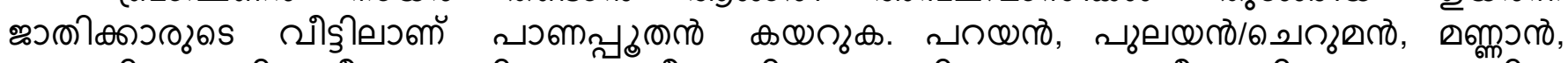
mว

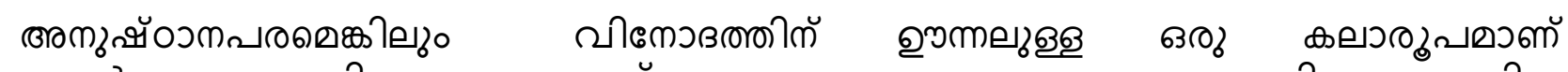

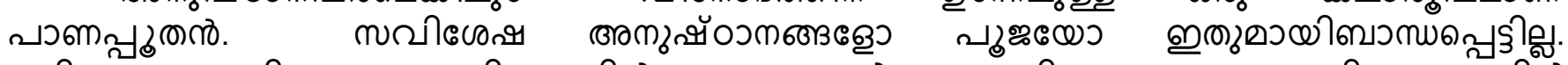

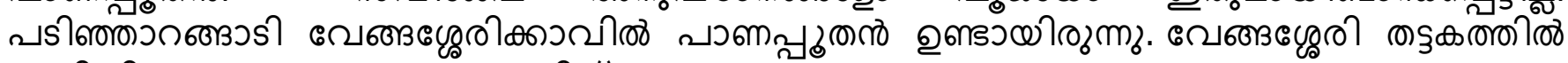

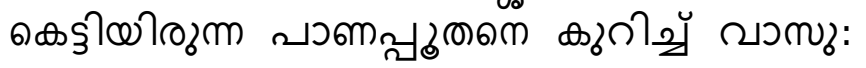

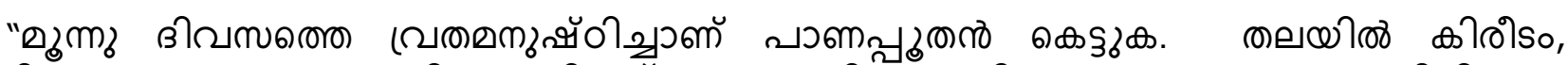

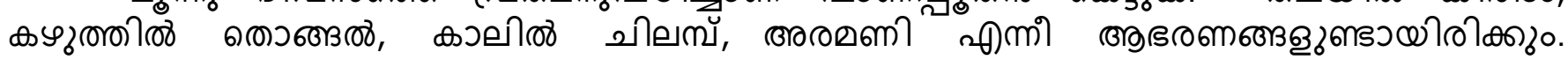

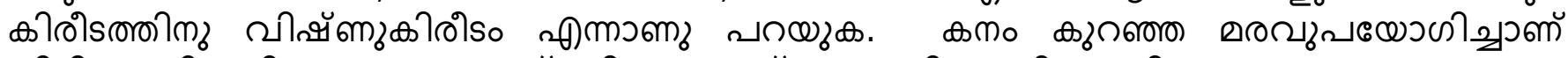

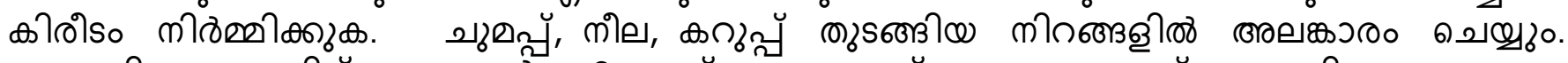

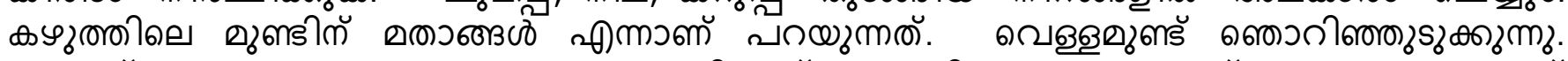

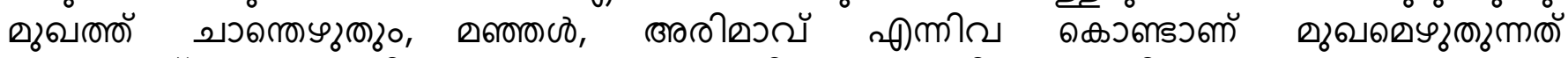

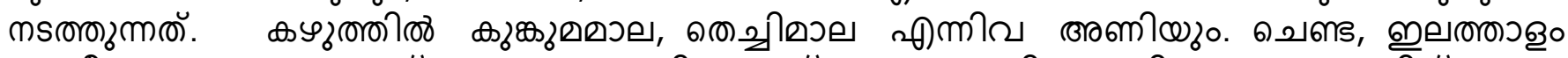

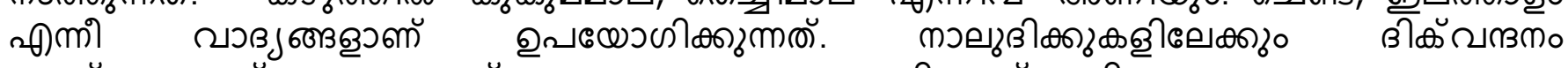

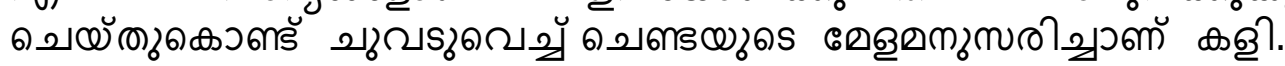

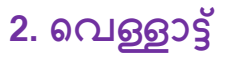

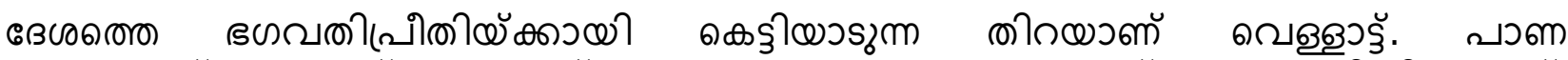

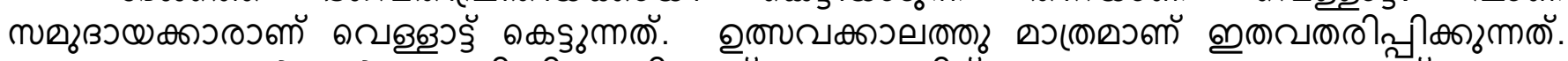

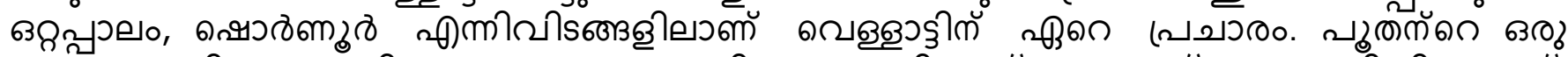

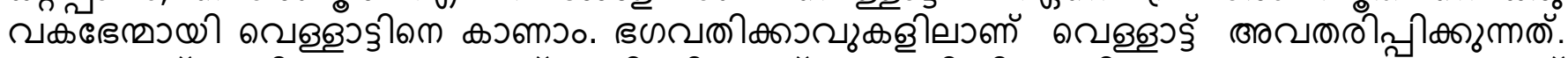
கால

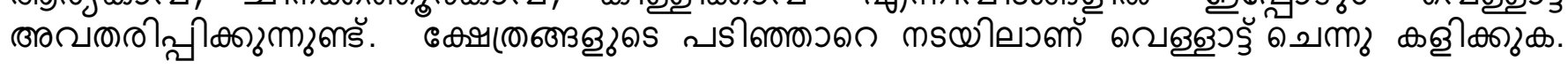

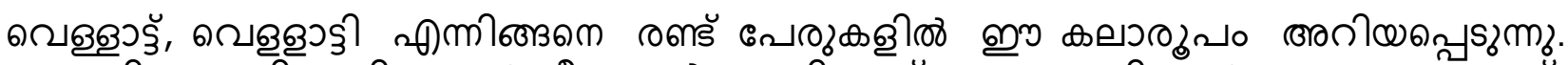

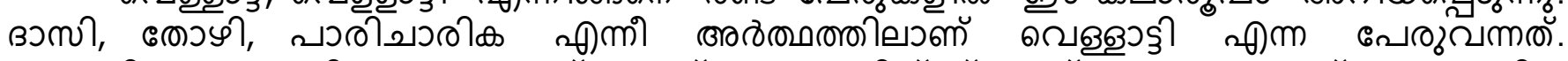

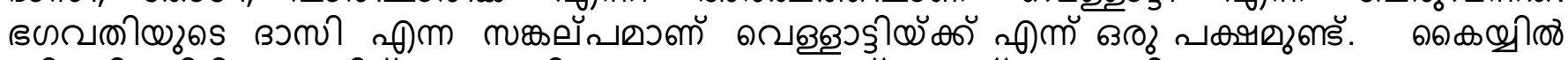

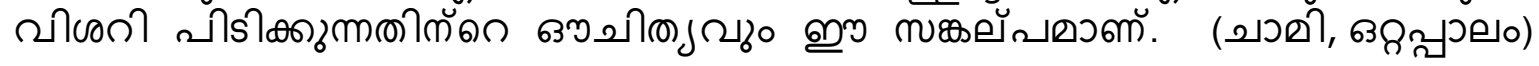




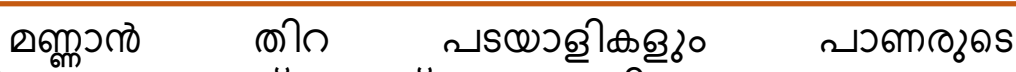

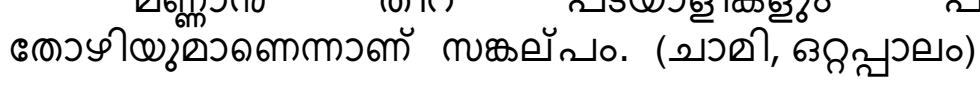

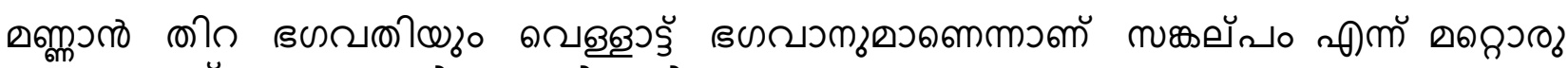

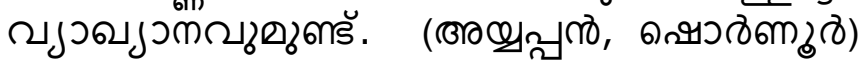

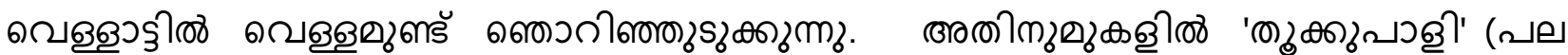

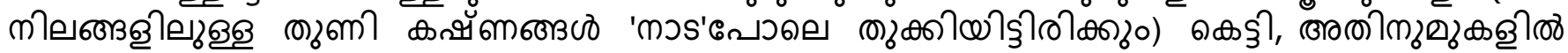

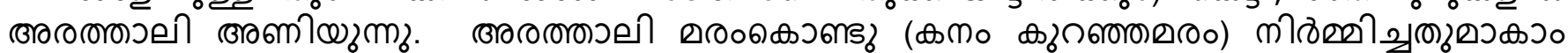

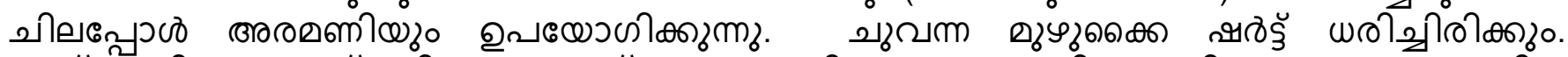

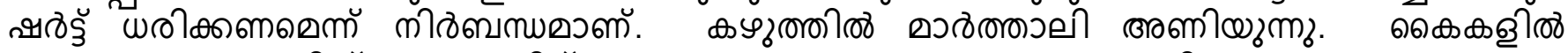

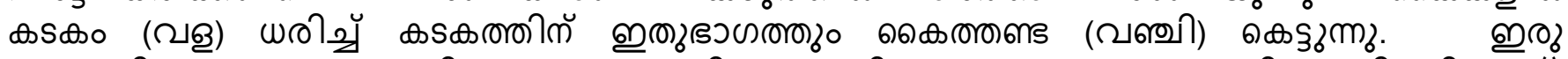

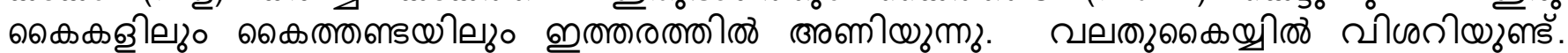

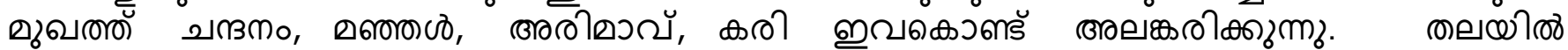

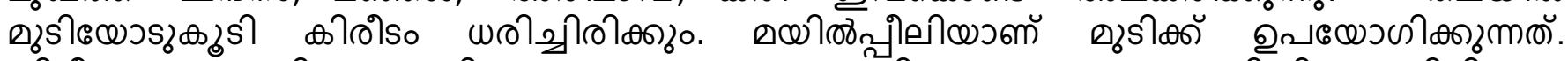

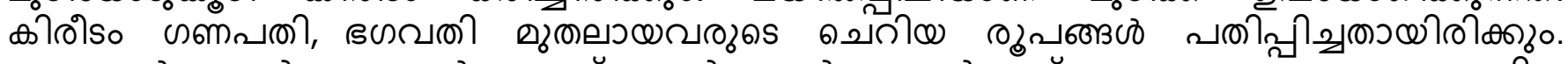

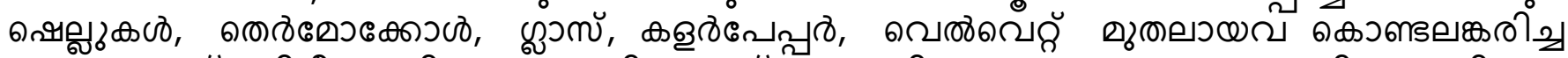
एவ్క

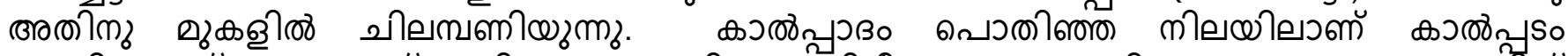

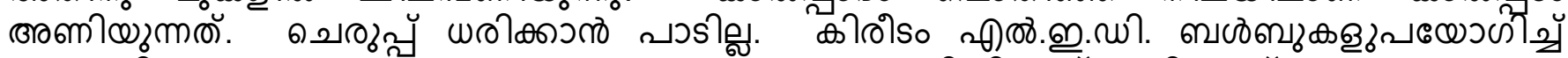

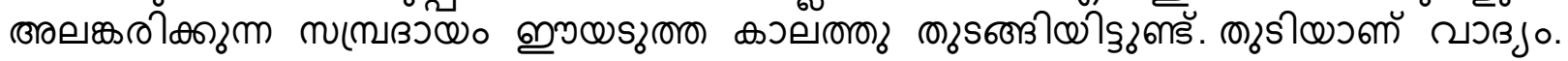

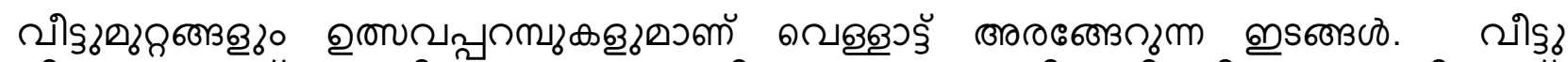

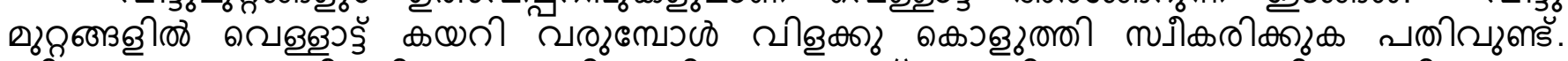

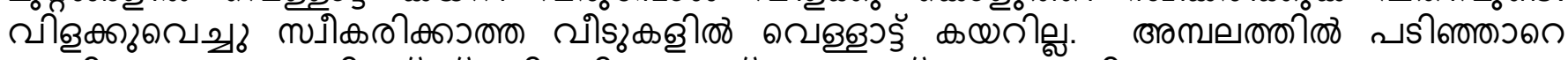

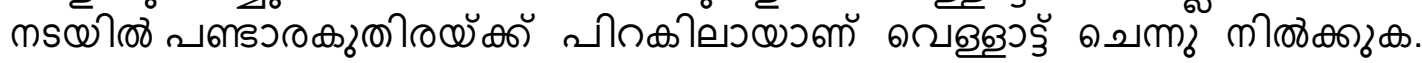

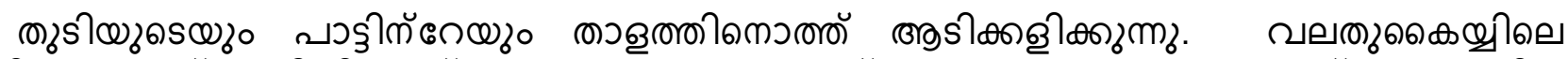

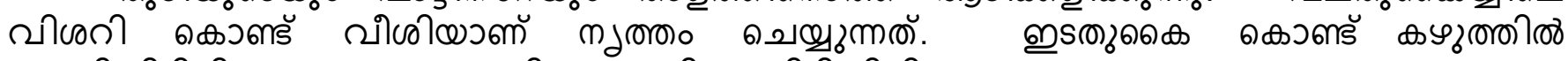

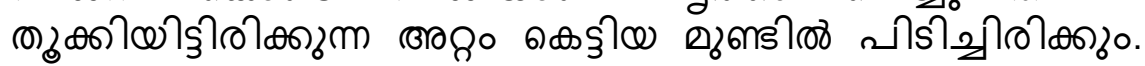

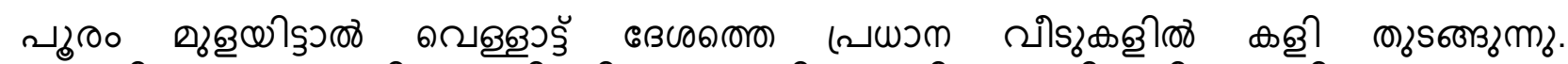

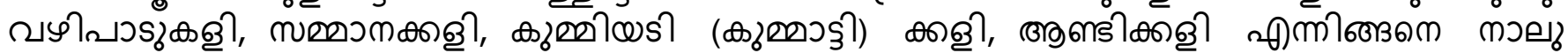

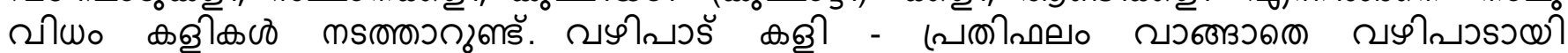

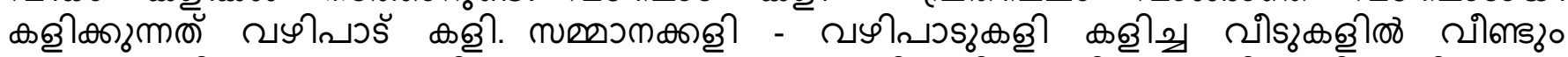

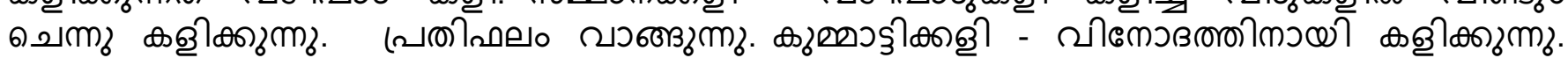

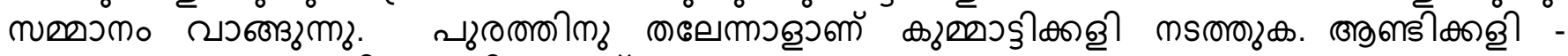

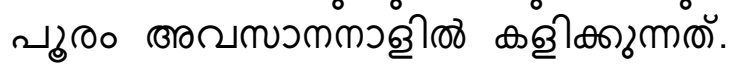

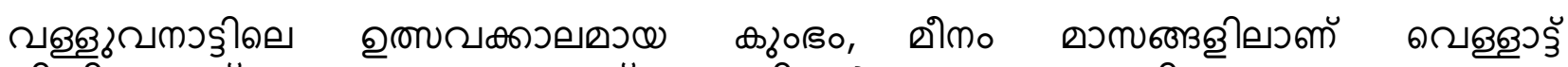

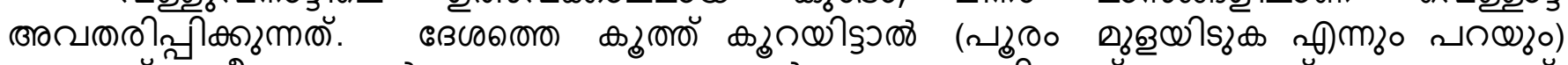

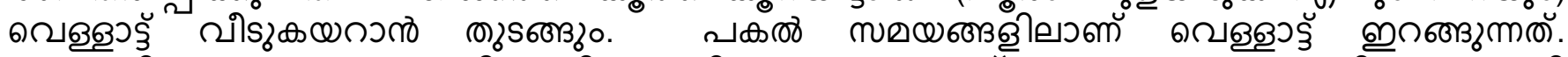

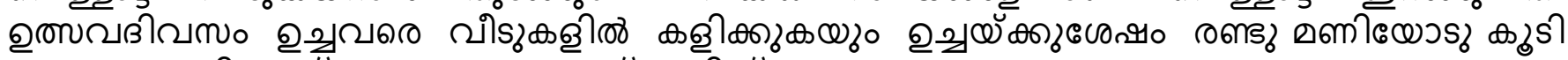
உஸாவ

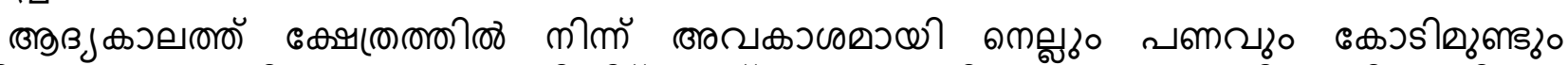

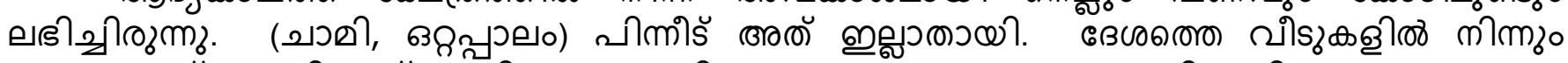

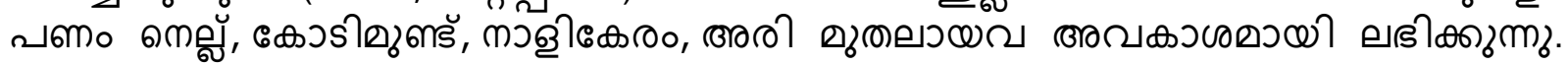

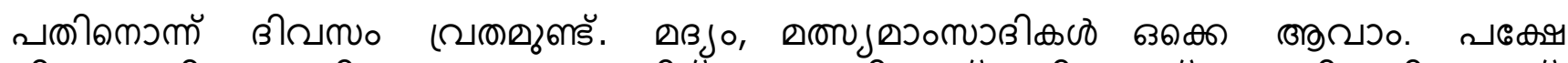

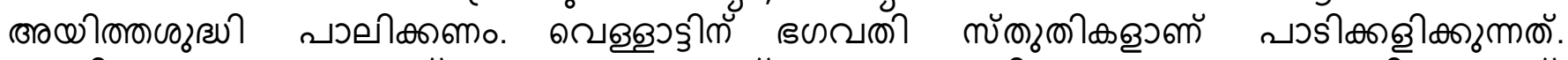

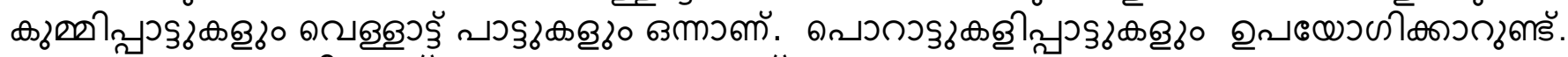

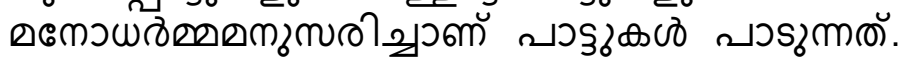




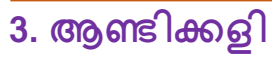

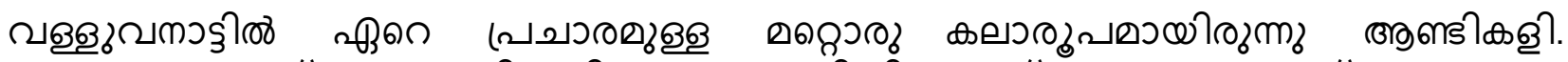

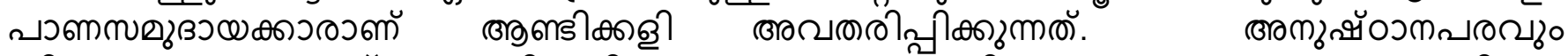

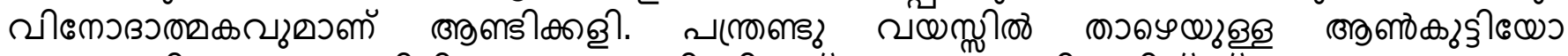

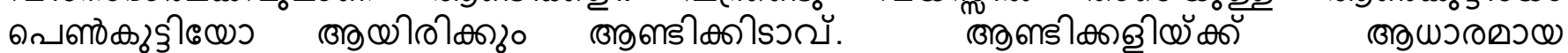

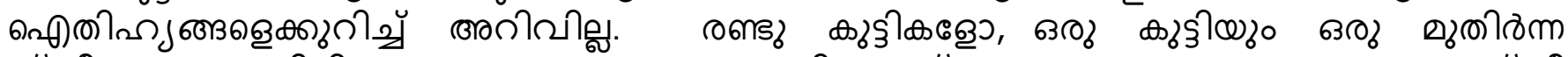

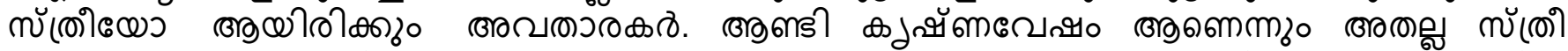

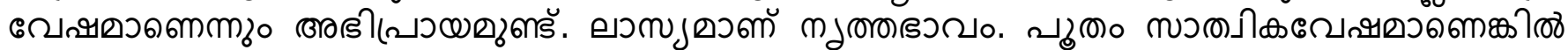

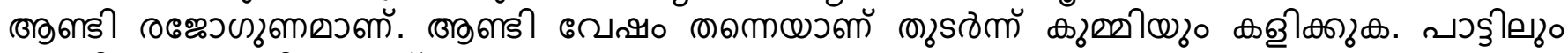

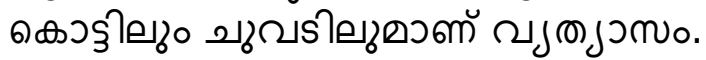

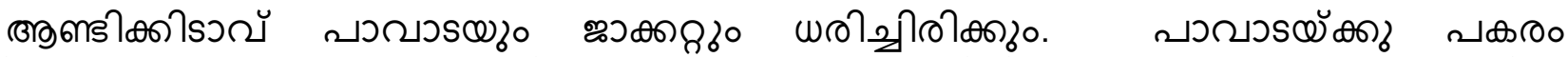

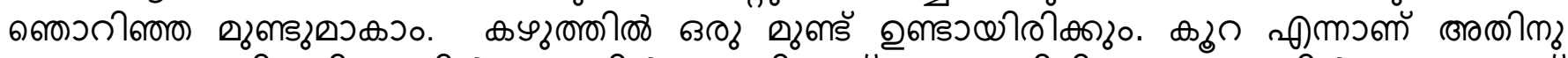

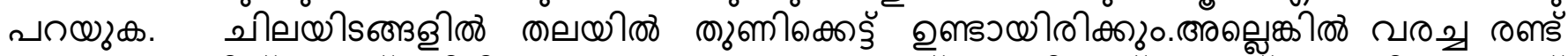

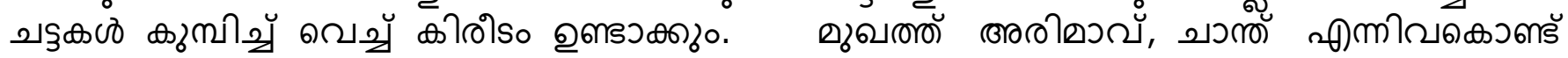

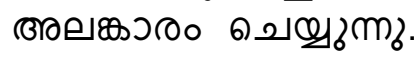

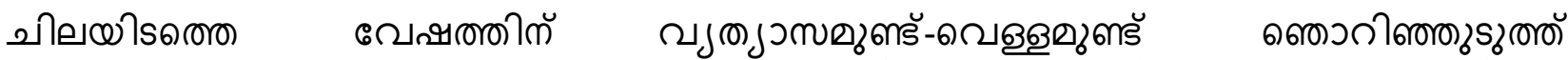

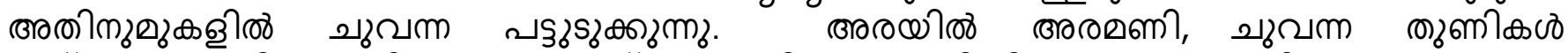

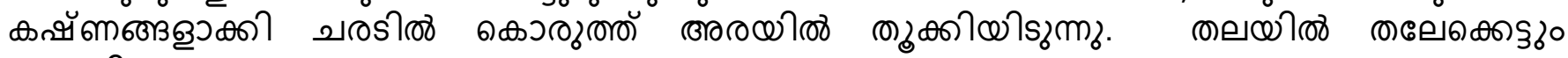

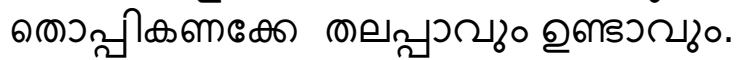

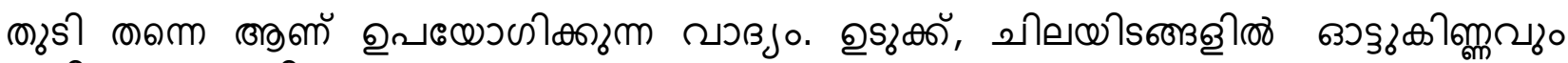

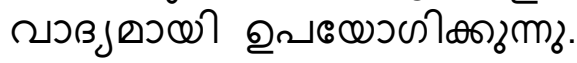

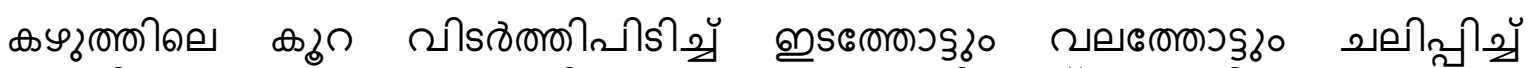

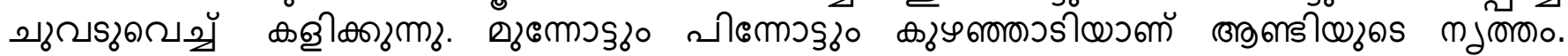

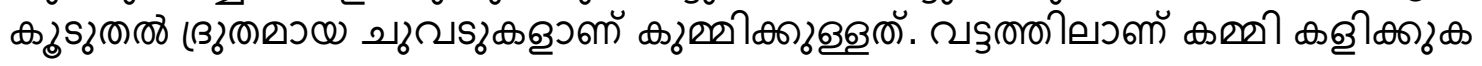

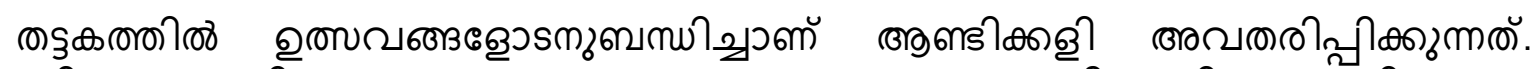

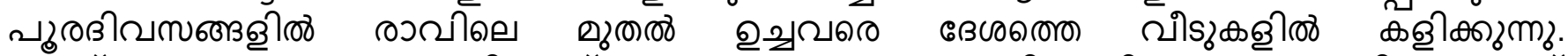

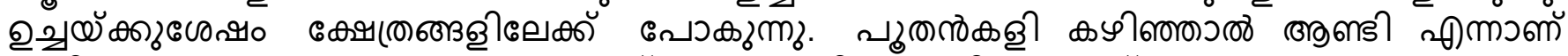

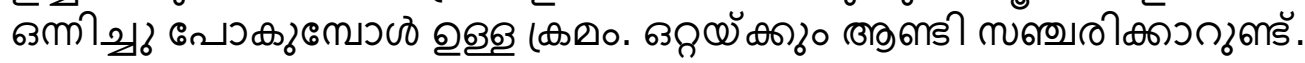

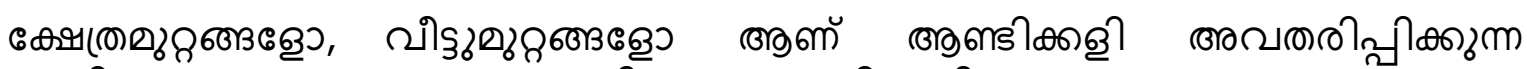

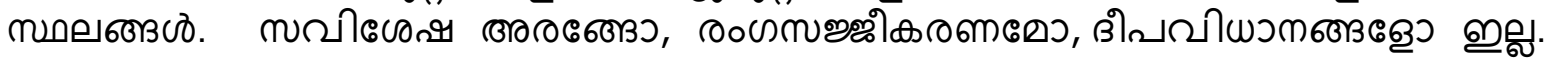

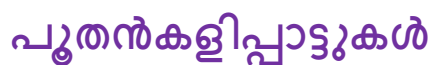

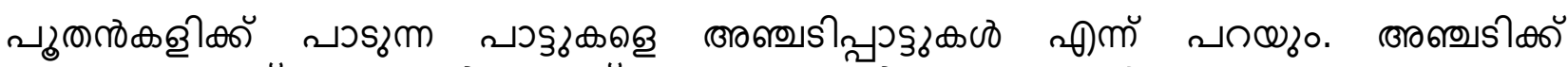

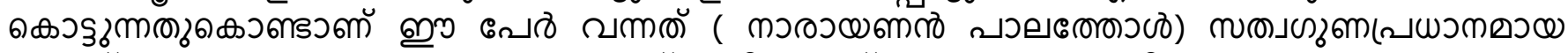

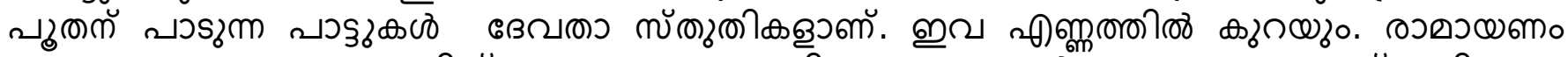

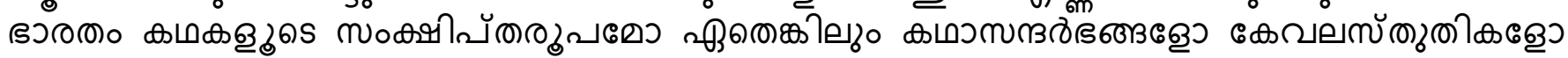
৫ाव Мว०.

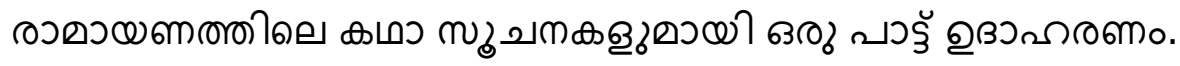

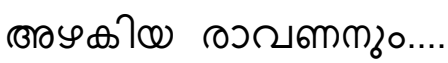

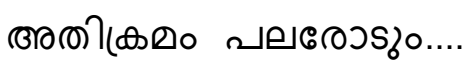

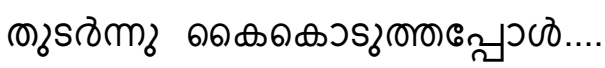

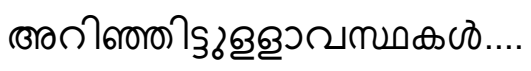

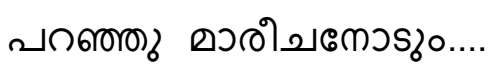

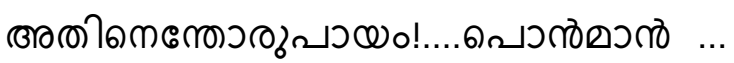




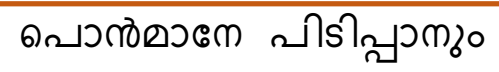

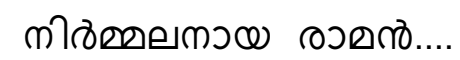

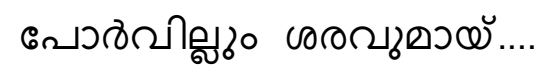

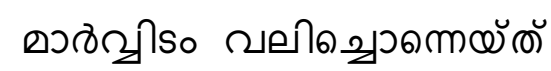

๑วตாடைை...

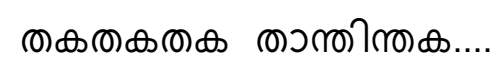

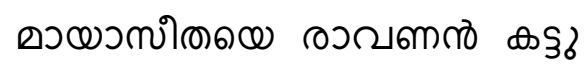

อக வூூவூழேग...

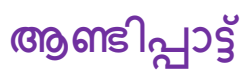

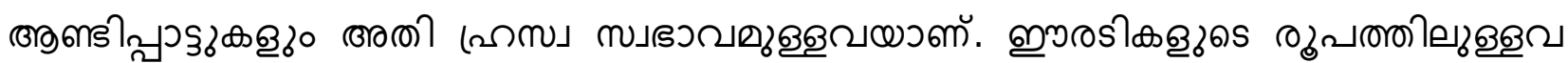

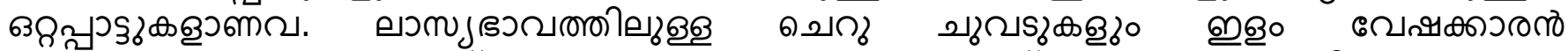

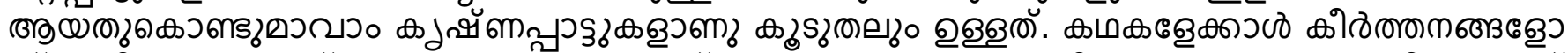

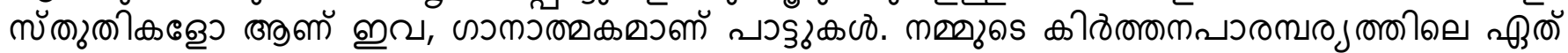

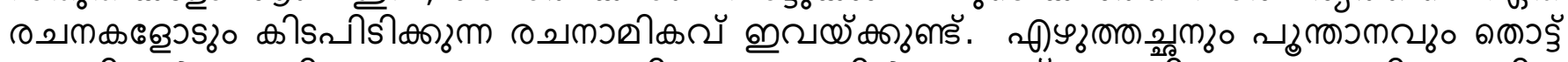

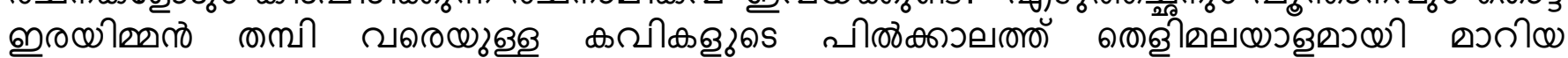

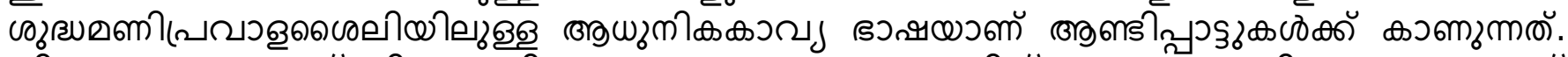
की

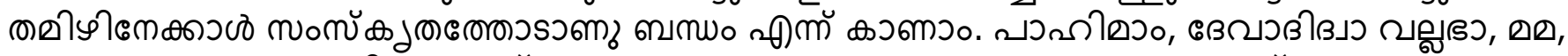

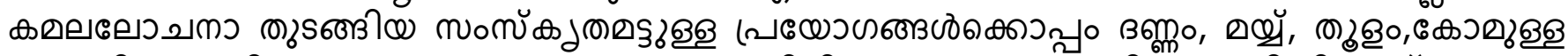

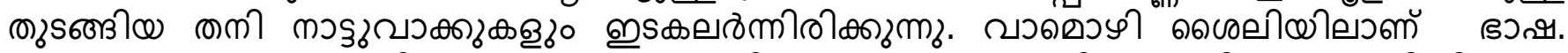

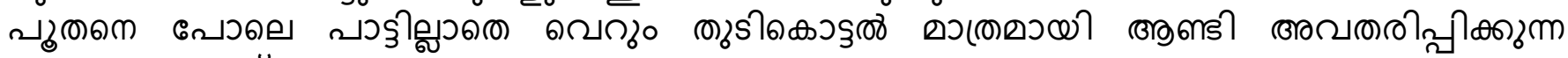

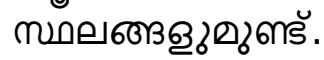

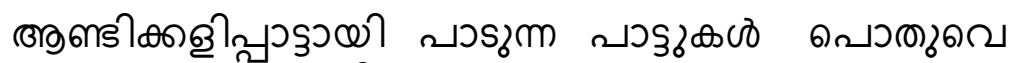

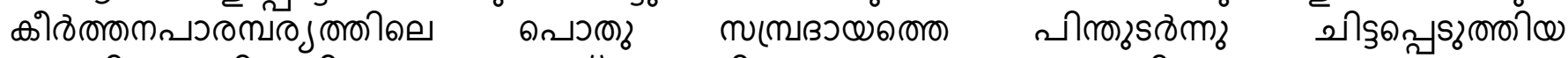

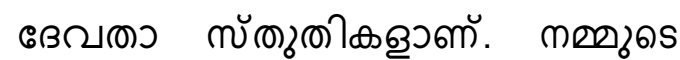

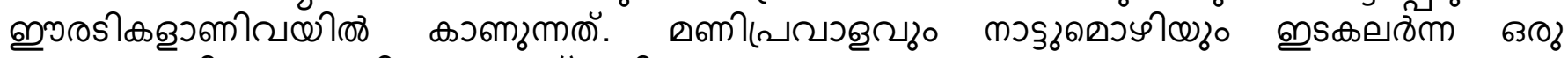

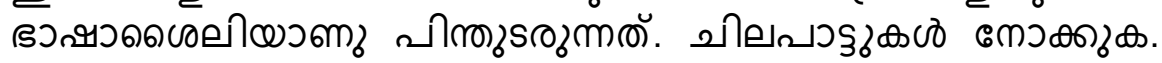

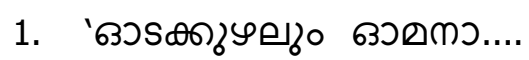

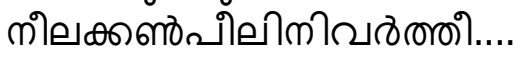

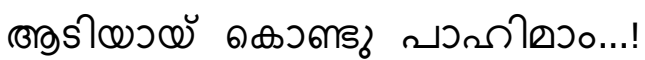

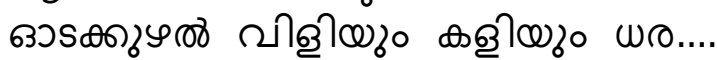

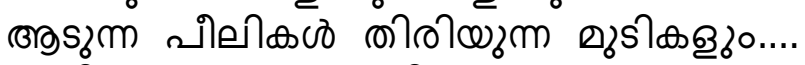

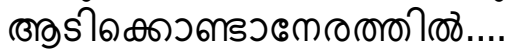

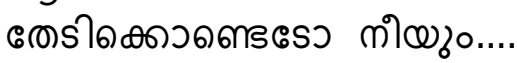

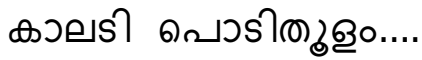

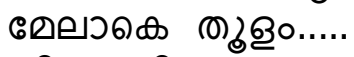

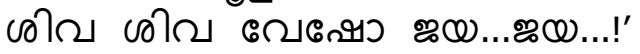

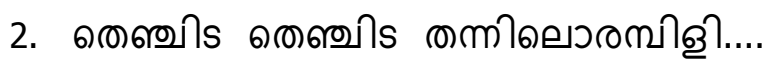

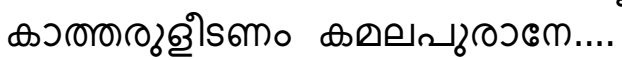

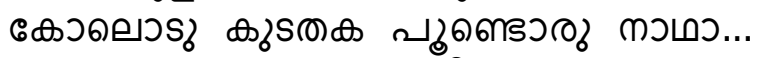

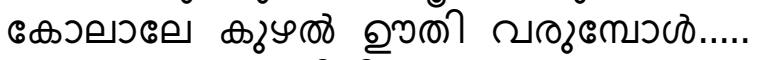

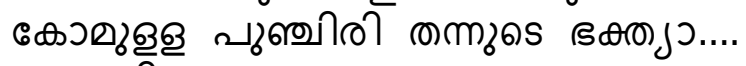

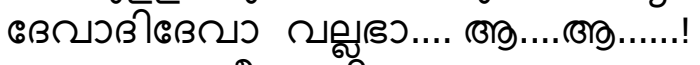

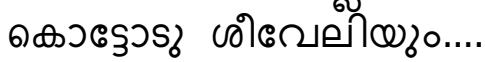

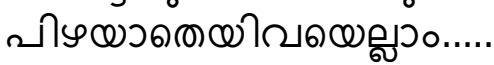




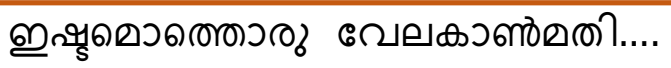

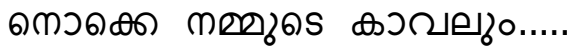

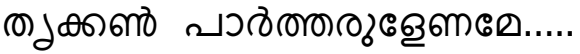

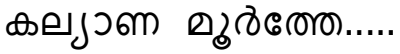

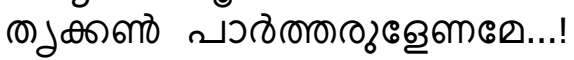

3. 'உற் mிهm குளேmவே

களรMวญிอேว...๑ه.....

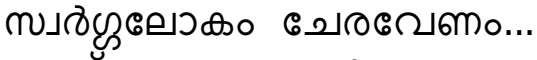

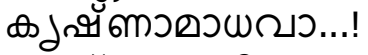

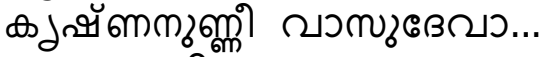

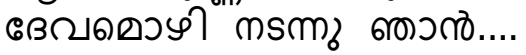

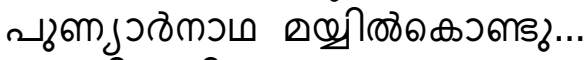

வुलडीडुmी ग....!

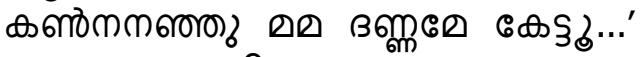

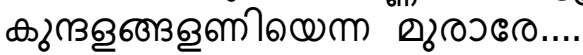

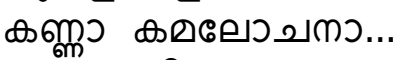

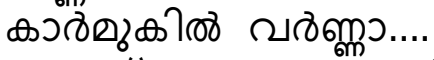

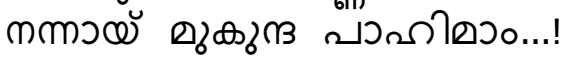

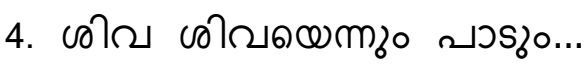

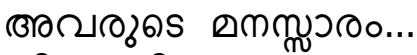

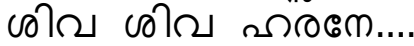

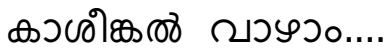

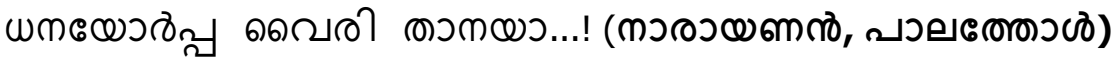

कुळी గ్రక్

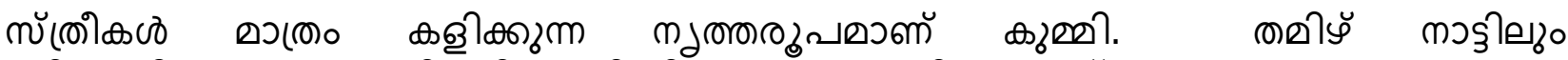

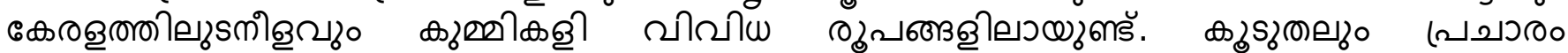

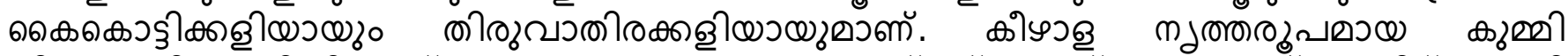

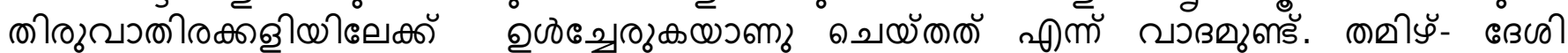

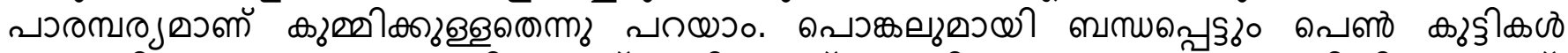

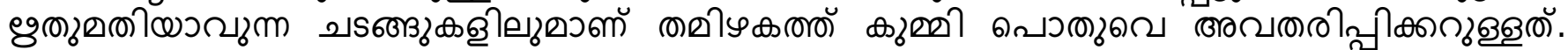

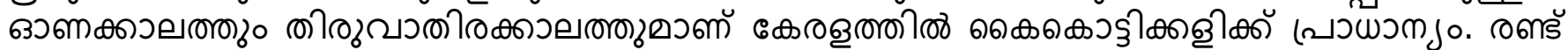

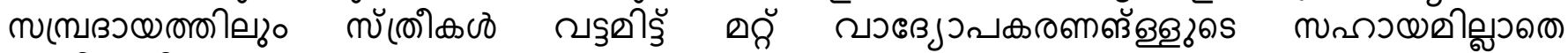

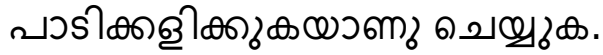

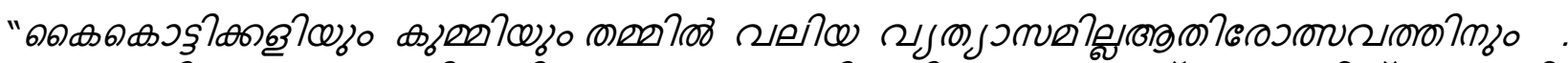

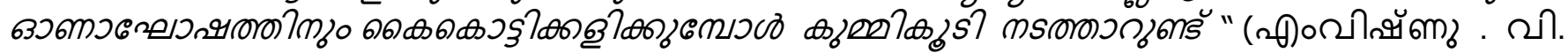

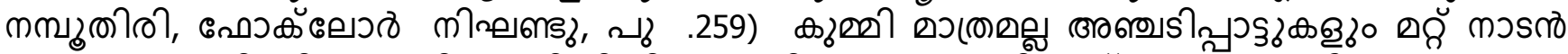

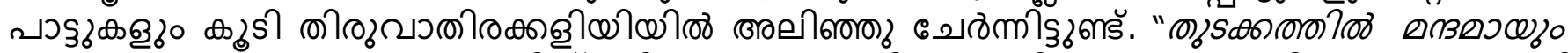

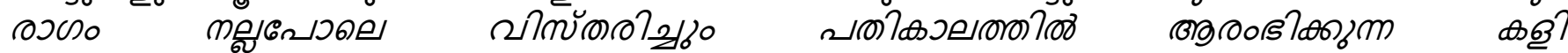

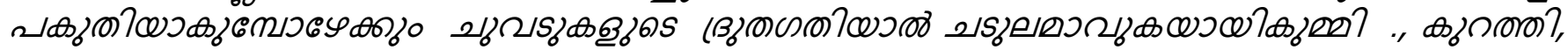

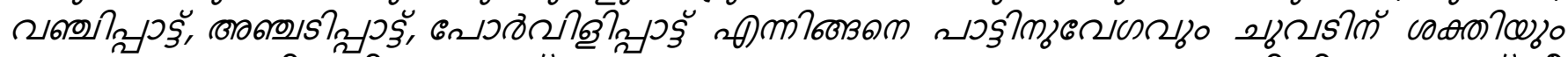

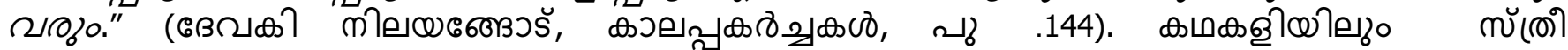

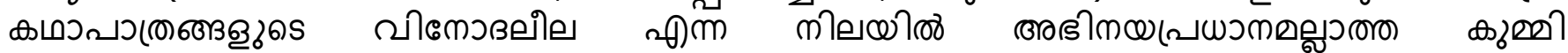

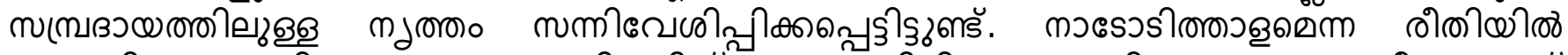

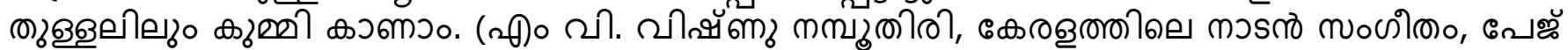

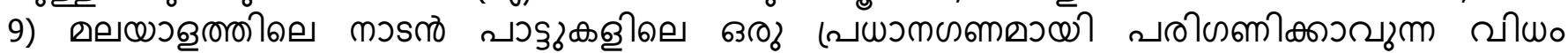

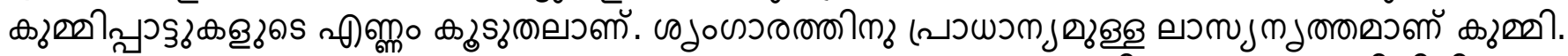

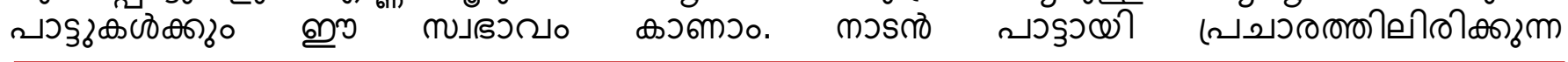




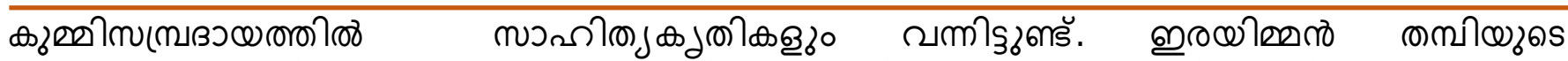

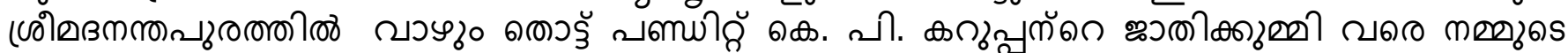

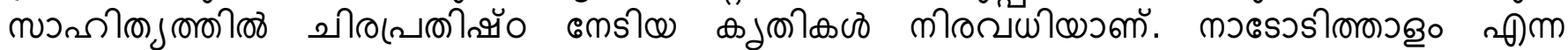

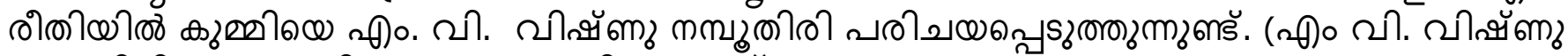

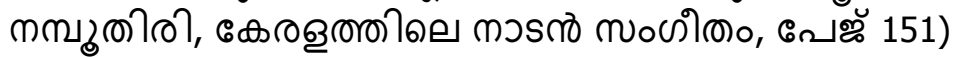

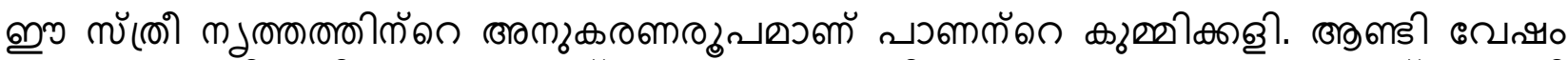

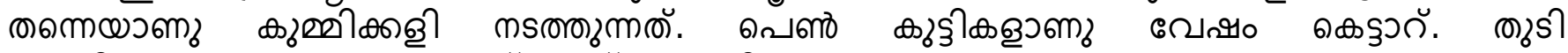

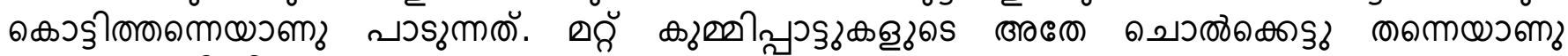

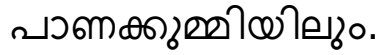

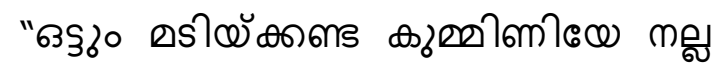

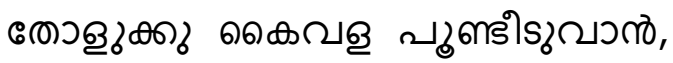

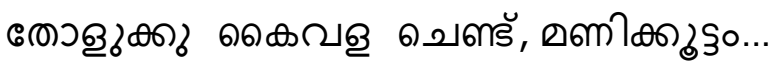

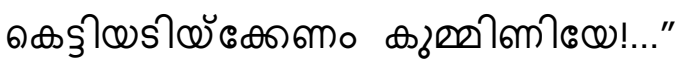

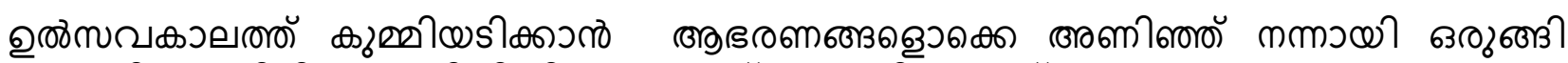

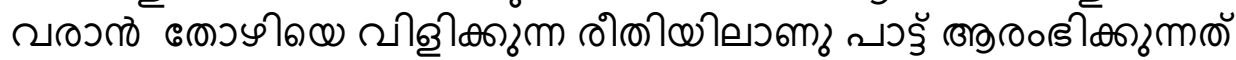

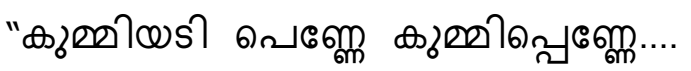

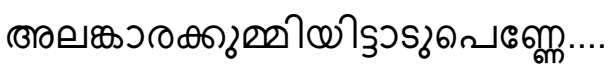

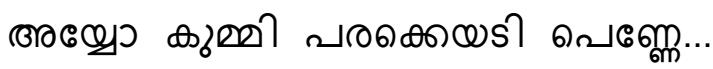

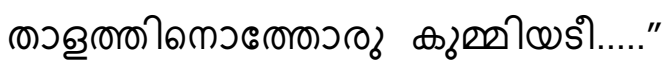

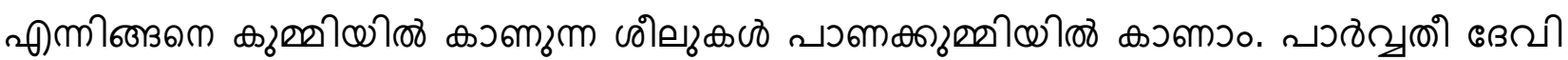

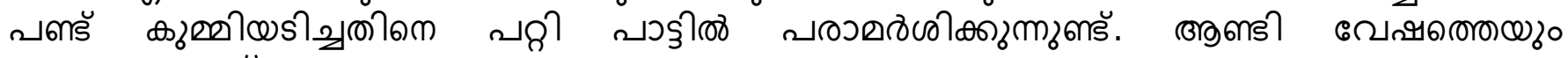

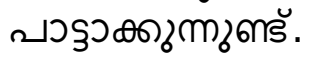

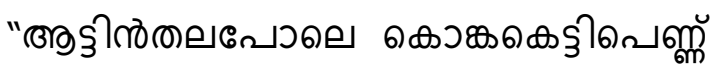

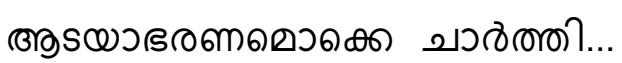

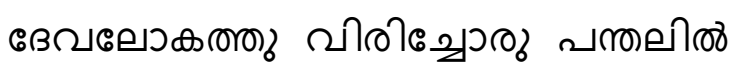

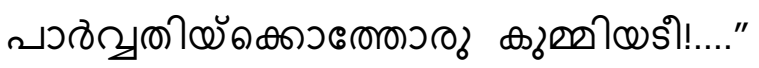

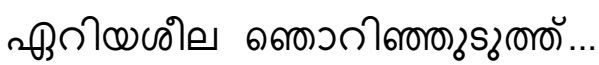

(B)

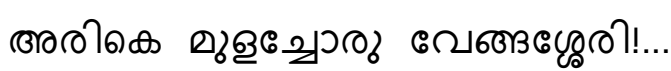

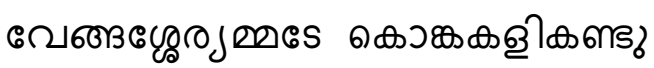

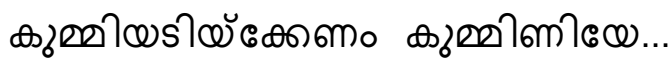

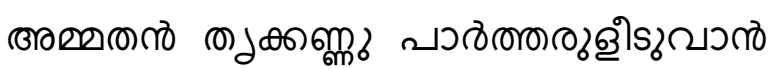

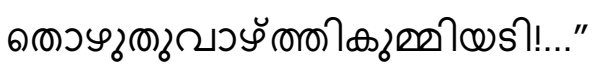

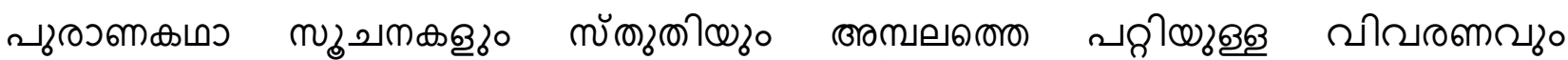

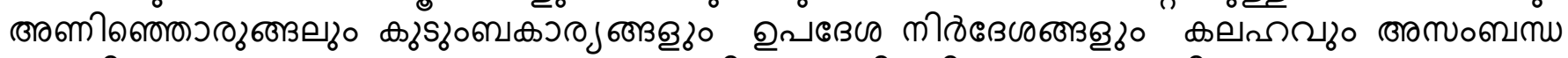

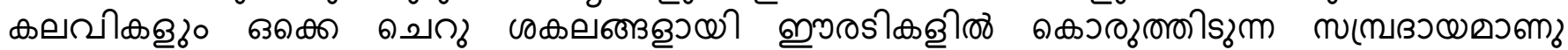

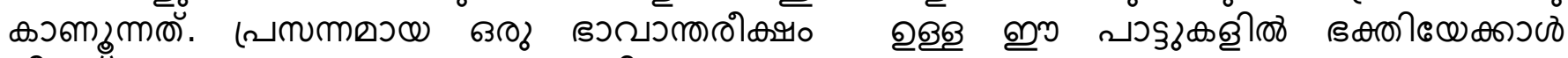

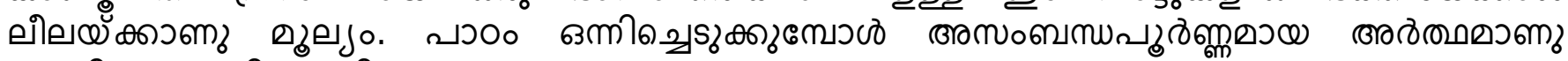

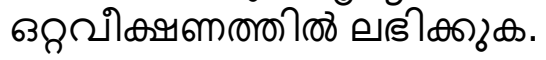

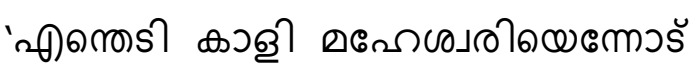




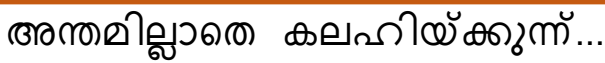

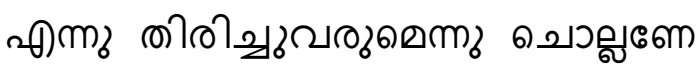

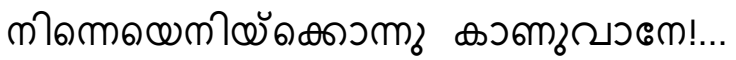

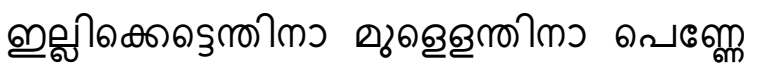

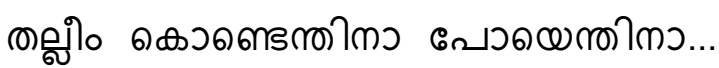

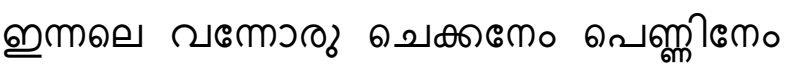

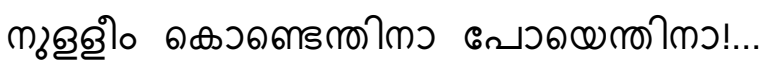

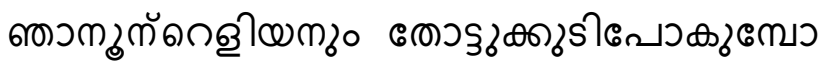

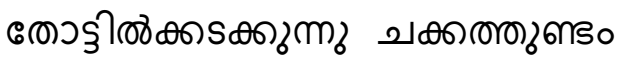

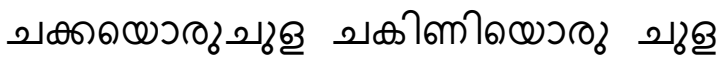

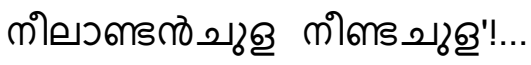

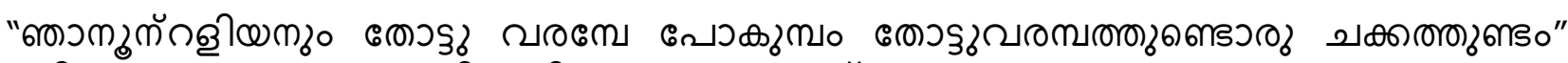

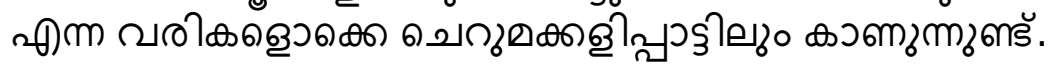

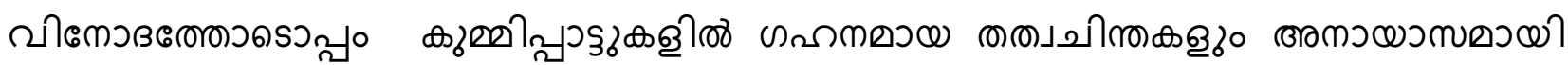
Asm? Мत्ठm].

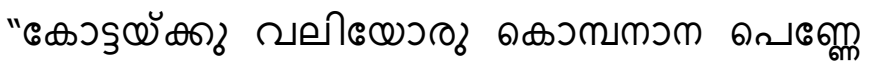

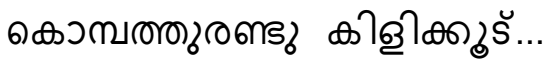

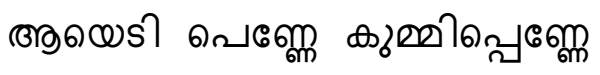

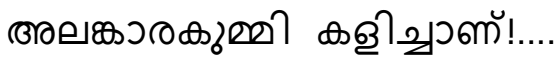

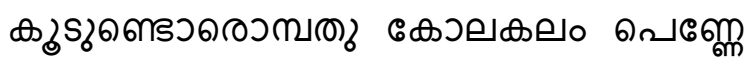

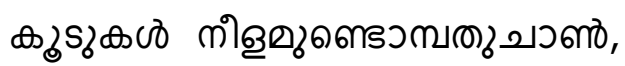

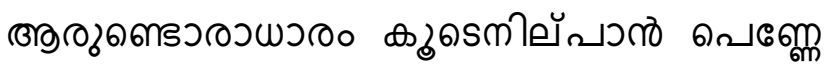

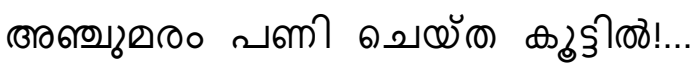

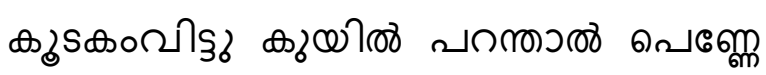

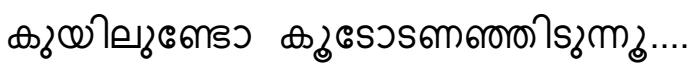

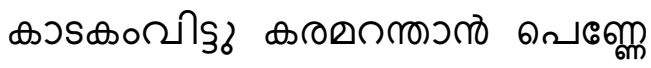

களிவாவும் வளு வலுவே!..."

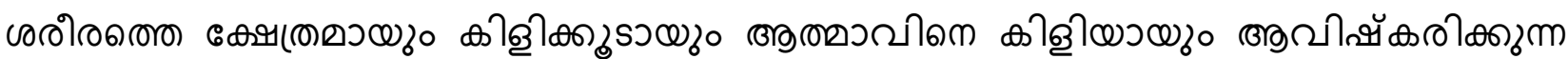

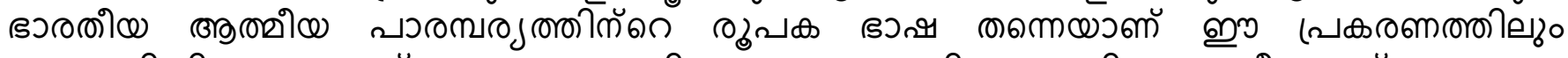

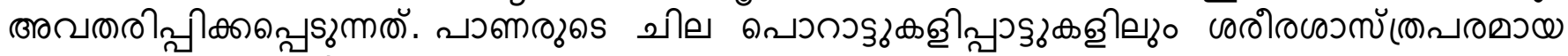

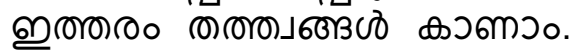

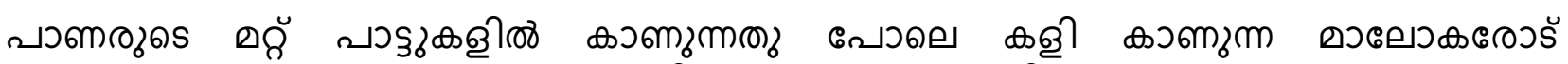

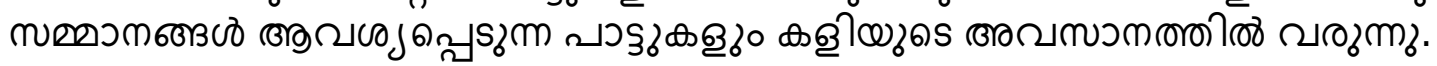

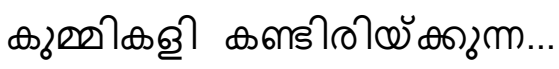

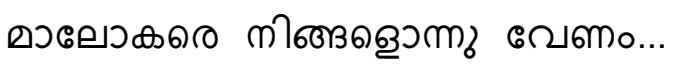

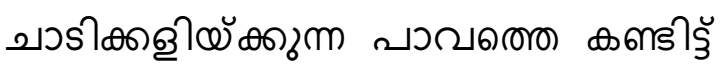

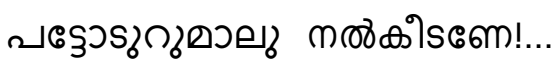

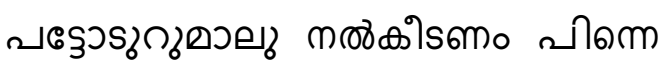




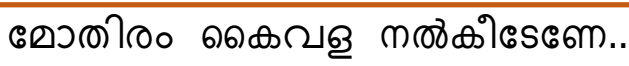

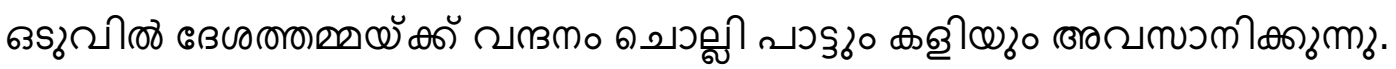

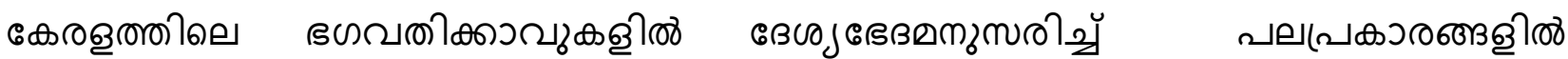

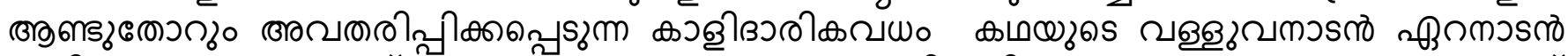

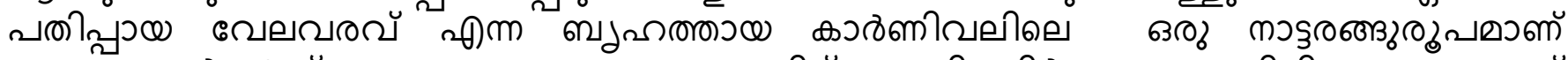

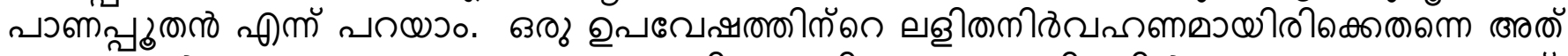

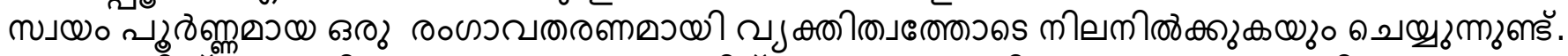

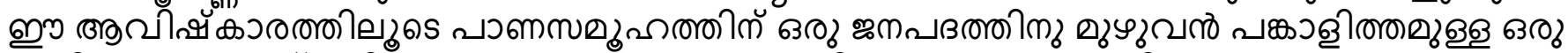

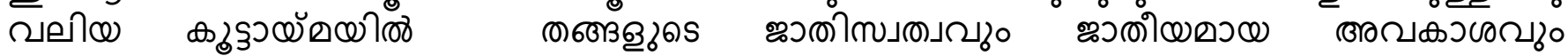

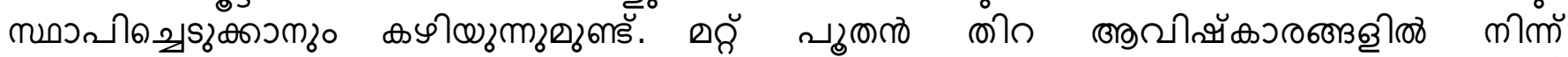

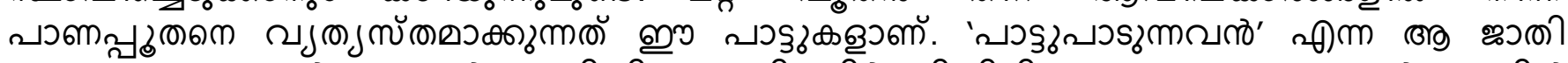

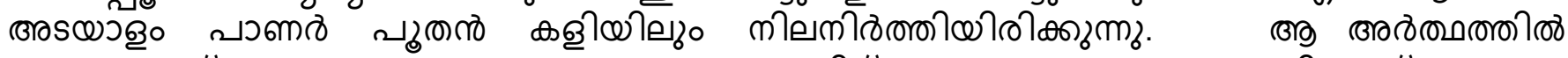

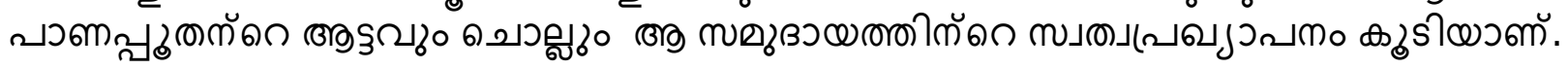

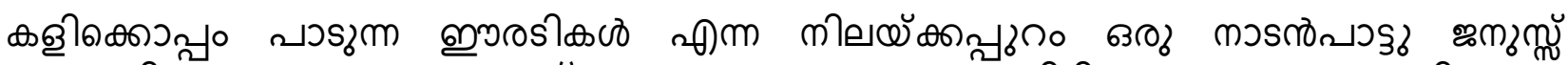

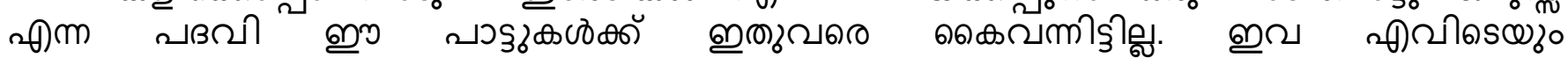

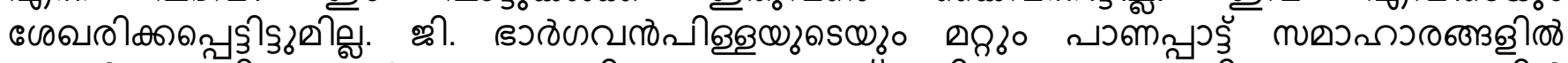

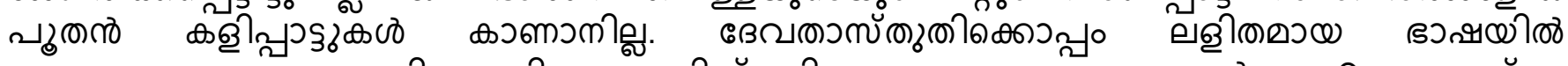

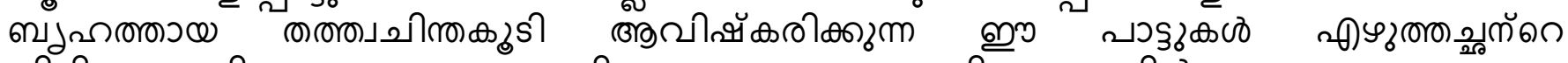

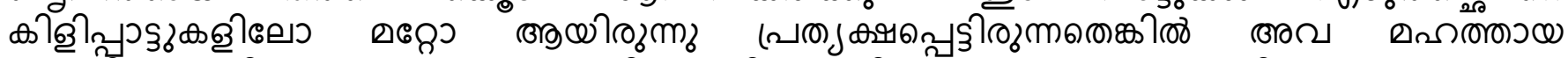

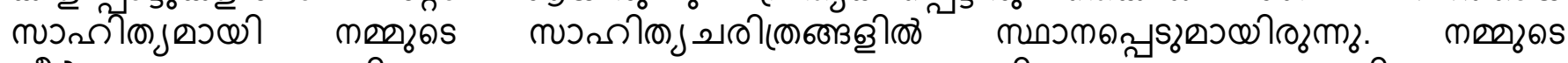

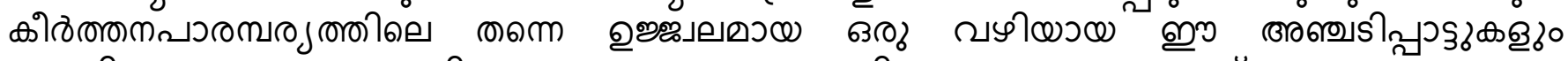

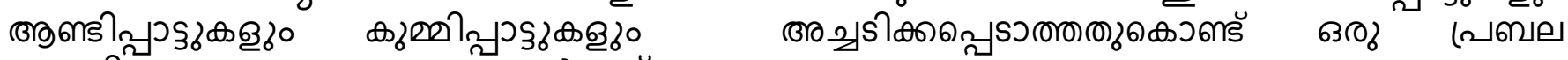

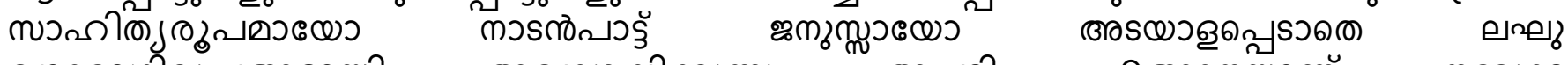

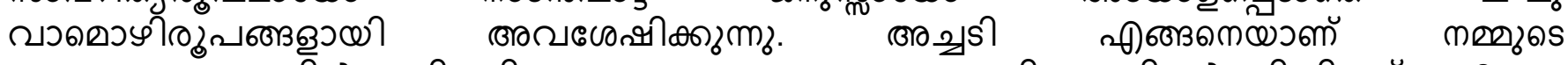

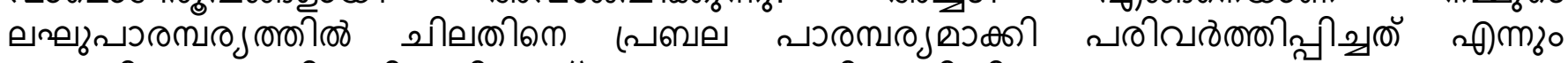

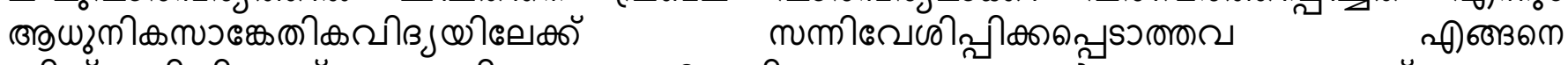

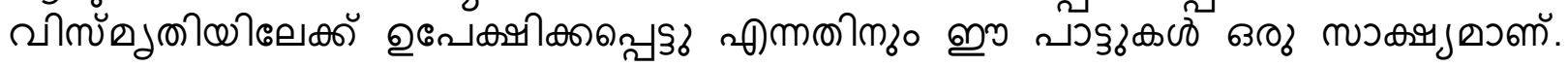

\section{References}

Bhargavan Pillai G, (2009), Keralathile Pananmar PattukaL N.B.S, Kottayam.

Devaki Niyankode, (2005), Kalaparachakal, Mathrubhoomi Books.

Folklore Nighantu, (1989), Kerala Bhasha Institute.

Malabarile Panapattukal (1981), SPSS, Kottayam.

Santhosh H.K., (1998), Folklore Vazhiyum Porulum, Samskrithi Publications.

Vishnu Namboodiri M.V., (2005), Keralathile Nadan Samgeetham Kerala Pathana Kendram.

\section{Informants}

Ayyappan (80), Mudinjaril Parambil, paruthipra, Shornur.

Chami K (63) Kattanapadi, Thottakara, Ottapalam

Narayanan (52) Palathole, Mattaya, Elamkulam.

Narayanan N P (55), Narukkottil, Chethallur

Raghavan (61), Kunnatheri ,Thekke Vavanur, Kootanad.

Vasu (66) Paruvakkappaliyalil, Thalakkasseri, Thrithala

\section{Funding}

No funding was received for conducting this study. 


\section{Conflict of interest}

The Author has no conflicts of interest to declare that they are relevant to the content of this article.

\section{About the License}

(C) The author 2021. The text of this article is open access and licensed under a Creative Commons Attribution 4.0 International License

\section{Cite this Article}

H.K. Santhosh, Poothan Kali Songs : an analysis of their types, themes and functions, Indian Journal of Multilingual Research and Development, Vol 2, Iss 1 (2021) 24-34. DOI: https://doi.org/10.34256/ijmrd2114 